\title{
Artigo
}

\section{"Paraísos perdidos": investimento estrangeiro direto em mineração e conflitos ecológicos distributivos no Brasil, na Colômbia e no Peru}

\author{
"Lost paradises": foreign direct investment in \\ mining and distributive ecological conflitcts in Brazil, \\ Colômbia and Peru
}

\section{Diego Freitas Rodrigues}

Centro Universitário Tiradentes (UNIT), Programa de Pós-graduação em Sociedade, Tecnologias e Políticas Públicas, Maceió, AL, Brasil

diegofreitasrodrigues@outlook.com

\begin{abstract}
Resumo: $\mathrm{O}$ aumento de volume de Investimento Estrangeiro Direto em Mineração, uma "oportunidade" para alavancar o crescimento econômico e desenvolvimento regional, contabiliza-se politicamente nos planos de desenvolvimento de países como o Brasil, a Colômbia e o Peru, ainda que o impacto da mineração seja elevado e muitas vezes não contabilizado nos seus estudos de impacto ambiental. Além das externalidades ambientais, existe o desenvolvimento de conflitos ecológicos distributivos em regiões atingidas pelo empreendimento mineral, como a Amazônica e Andina, resultante muitas das vezes da ausência de mecanismos de consulta prévia. É possível haver uma associação entre o IED destinado ao extrativismo minerário e os conflitos ecológicos distributivos em países com alto ingresso de IED como se configuram o Brasil, a Colômbia e o Peru? O objetivo do trabalho foi identificar um panorama do ingresso de IED nos países e se o mesmo se associou a melhores indicadores sociais nas regiões minero-dependentes e se houve correspondência de conflitos ecológicos distributivos vinculados a mineradoras transnacionais. Para tanto, utilizou-se de metodologia mista, empregando de forma concomitante e comparada a análise de dados secundários de entrada de IED e indicadores sociais nas regiões minero-dependentes nos países, além de análise de imagens de satélite de empreendimentos minerários por meio do Google Earth. Os resultados indicam uma agenda e investimento político em comum dos países na atração
\end{abstract}


de IED para mineração, ao mesmo tempo em que há significativa fragilidade dos mecanismos de controle social, como a Consulta Prévia, nos empreendimentos minerários licenciados, estimulando conflitos similares nos três países.

Palavras-chave: IED; Mineração; Conflitos ecológicos distributivos.

\begin{abstract}
The volume increase of Foreign Direct Investment in Mining, an "opportunity" to leverage economic growth and regional development, is politically counted in the development plans of countries such as Brazil, Colombia and Peru, although the impact of mining is high and often not accounted for in its environmental impact studies. In addition to the environmental externalities, there is the development of distributive ecological conflicts in regions affected by the mineral enterprise, such as the Amazonian and Andean regions, often resulting from the absence of prior consultation mechanisms. Is it possible to have an association between the FDI destined to mineral extractivism and the distributive ecological conflicts in countries with high FDI inflows such as Brazil, Colombia and Peru? The objective of this research was to identify a prospect of the FDI inflow in the countries and whether it was associated with better social indicators in the mining-dependent regions and if there was correspondence of distributive ecological conflicts linked to transnational mining companies. For that, a mixed methodology was used, concomitantly and comparing the analysis of secondary data of entry of FDI and social indicators in the mining-dependent regions in the countries, besides analysis of satellite images of mining projects through Google Earth. The results indicate a common agenda and political investment of the countries in attracting FDI to mining, while there is significant fragility of social control mechanisms, such as the prior consultation, in licensed mining ventures, stimulating similar conflicts in the three countries.
\end{abstract}

Keywords: FDI; Mining; Distributive ecological conflicts.

\title{
Introdução
}

O Brasil, a Colômbia e o Peru são três países de mega biodiversidade, ambos compartilhando de um mesmo bioma, no caso o amazônico, e possuem um patrimônio natural ainda não inteiramente precificado. E aí reside um dos maiores problemas na tomada de decisão política envolvendo esse patrimônio natural e sua exploração: do ponto de vista econômico ecológico, a maior parte da natureza encontra-se fora do mercado, entretanto, sofre os efeitos colaterais de sua exploração. De forma paralela, tanto o Brasil quanto a Colômbia e o Peru registraram significativos volumes de Investimento Estrangeiro Direto (IED) nos últimos 10 anos, boa parte deles de caráter extrativista e direcionados ao extrativismo minerário.

O aumento de volume de IED contabiliza-se como a oportunidade para alavancar o crescimento econômico e desenvolvimento regional dos países, credita-se a crença comum das agendas governamentais latino americanas. E há "fundamento econômico" para essa "crença" entre os decisores políticos. Para Davis (1998) e Radetzki (1982), a mineração é um estágio para o desenvolvimento dos países, argumentação esta reforçada 
pelo Banco Mundial. Para a CEPAL (2012), a liberalização do IED resultaria no aumento nas taxas de investimento, o que levaria a um maior crescimento econômico dos países.

Com uma perspectiva menos otimista, Ross (2001) afirma que os países que possuem sua matriz produtiva baseada na dependência de exploração mineral têm níveis de desigualdade maiores que aqueles países que não possuem essa dependência e uma renda per capita similar, resultando na máxima de que maior o peso dos minérios nas exportações de um país, menor a parcela de renda que cabe aos 20\% mais pobres do país, cenário propenso a potencialização de conflitos ecológicos distributivos, assim definidos por Alier e Jusmet (2013, p. 104-105): :[...] por distribuición ecológica se entienden los patrones sociales, espaciales y temporales de acceso a los benefícios obtenibles de los recursos naturales y a los servicios proporcionados por el ambiente".

Ainda que esse debate ocorra nas literaturas de Ciência Política e Economia e terminem por refletir nas políticas de financiamento de bancos de investimento (como o Banco Mundial e o BNDES no Brasil) e relatórios promovidos por organizações internacionais destinadas ao planejamento e desenvolvimento econômico latino americano (o caso da (EPAL), parte das iniciativas governamentais comuns para estimular o crescimento econômico dos países latino americanos de forma geral nos últimos 10 anos aproveitaram o boom das commodities e garantindo o "fôlego político" de muitos governos da região, foi a flexibilização do acesso de IED nos mercados locais, assim como sugeria a CEPAL. Como um todo, especialmente os governos dos países da América do Sul ao mesmo tempo que consolidaram, grosso modo, seus regimes democráticos (com eleições livres e pluripartidárias e maior grau de liberdade de imprensa e independência do Judiciário em maior ou menor intensidade entre os países), também reduziram suas barreiras para a entrada de investimento estrangeiro e, em geral, também reduziram o papel do Estado na economia.

Se os bens e serviços ambientais e ecossistêmicos não se encontram inteiramente precificados, o mesmo não pode se dizer dos minérios (um recurso natural esgotável) disponíveis no bioma amazônico compartilhado por Brasil, Colômbia e Peru, na sua maior parte já identificadas em suas maiores jazidas e com valor de mercado, o que termina por atrair interesses de empresas mineradoras (transnacionais ou nacionais associadas a estrangeiras) e, por conseguinte, fazem "soar o alarme" de oportunidade política de atração de capital privado para explorar a diversidade desses bens ambientais 
e, credita-se, para alavancar o crescimento econômico e desenvolvimento das regiões mineradoras e, por conseguinte, dos países.

É possível, portanto, haver uma associação entre o IED destinado ao extrativismo minerário e os conflitos ecológicos distributivos em países com alto ingresso de IED como se configuram o Brasil, a Colômbia e o Peru? O objetivo do trabalho foi identificar se o ingresso de IED resultou em melhores indicadores sociais nas regiões minero-dependentes e se há correspondência de conflitos ecológicos distributivos associados a mineradoras transnacionais. Para tanto, utilizou-se de metodologia mista, empregando de forma concomitante e comparada a análise de dados secundários de entrada de IED e indicadores sociais nas regiões minero-dependentes nos países, além de análise espacial de empreendimentos minerários com dados georreferenciados por meio do Google Earth.

Para cumprir com esse objetivo, o trabalho foi dividido em duas etapas: a primeira identificou a atração de IED para o extrativismo minerário como uma política de desenvolvimento comum a Brasil, Colômbia e Peru e, na segunda etapa, mapeou-se os efeitos dessa política de desenvolvimento amparada no extrativismo minerário em indicadores sociais nas regiões minero-dependentes, suas principais fragilidades político-institucionais envolvendo a mega mineração e o escalonamento de conflitos ecológicos distributivos, com especial atenção naqueles na região amazônica, bioma compartilhado por ambos os países.

\section{Investimento Estrangeiro Direto na América Latina: o extrativismo como política de desenvolvimento}

De acordo com dados da CEPAL (2012), a América Latina foi alvo do IED nos últimos anos. Por exemplo, o Brasil obteve um recorde de 87\% de entradas de IED em 2010, tornando-se o maior receptor na América do Sul, passando de US\$25,9 bilhões em 2009 (R\$ 41,3 bilhões) para US\$ 48,4 bilhões (R\$ 76,9 bilhões), enquanto o Peru atingiu as cifras de US\$ 7,3 bilhões e a Argentina apenas de US\$ 6,2 bilhões, perfazendo um diferencial substancial entre os países. A atratividade brasileira ao IED já superava de

1 É importante destacar que a busca por atrair IED resultou, por parte do Peru, na criação da Prolnversión, a Agencia de Promoción de la Inversión Privada. 
T\&P "Paraísos perdidos": investimento estrangeiro direto em mineração e conflitos ecológicos distributivos no Brasil, na Colômbia e no Peru

forma assertiva, no auge da crise econômica internacional, a entrada de IED no Peru, na Argentina, no México e na Colômbia, acrescentando que entre os anos de 2009 e 2010 tanto o Brasil quanto a Argentina e o Peru tiveram uma entrada maior de IED no ano de 2010, enquanto na Colômbia ocorreu o contrário, 2009 foi um ano de maior receptividade de IED.

Particularmente, o caso peruano chama a atenção. Os governos peruanos fomentaram nos últimos anos uma série de políticas cujo objetivo foi facilitar a participação da iniciativa privada no desenvolvimento da infraestrutura do país, criando, por exemplo, um regime de concessões, regido pelo Decreto Legislativo no 839/2006, para atração de investimentos privados. Comparativamente, no caso brasileiro, a ampliação do IED se deveu especialmente (1) à estabilização econômica e (2) às reformas estruturais associadas à privatização nos anos 1990, que foram amparadas por diversos instrumentos legais, como a Emenda Constitucional n08, de 15/08/95, cujo objetivo foi a eliminação do monopólio estatal sobre os serviços de telecomunicações; a Lei 9.472, de 16/07/97, que regulamentou as concessões desses serviços; e, por fim, a Lei 9.491, de 09/09/97, cujo objetivo foi suprimir os limites de participação do capital estrangeiro em empresas privatizadas (CEPAL, 2012)2.

Os destinos setoriais do IED variam segundo a sub-região receptora. Na América do Sul, por exemplo, os setores com maior recebimento em 2010 foram os de recursos naturais e os de serviços, com 43\% e 30\% de participação, respectivamente. Nesta sub-região mantém-se a elevada importância das commodities e, em comparação com 2005-2009, observa-se inclusive um aumento do peso dos setores primários nos investimentos, no qual o setor de Recursos Naturais aumentou 10\% em 2010 em relação a 2009, já ultrapassando outros setores como Manufaturas e Serviços na América do Sul (CEPAL, 2012). De acordo com o relatório da CEPAL (2012), na América do Sul (sem incluir o Brasil): "[...] consolidou-se um padrão setorial em que os recursos naturais - em particular a mineração - foram o principal destino do IED (51\% em 2012), enquanto as manufaturas e os serviços captaram 12\% e 37\%, respectivamente". Ou seja,

2 É importante reforçar que, no caso colombiano, os conflitos do Estado com guerrilhas de Esquerda (como as FARC) e paramilitares de Direita promoveram um atraso na atração de IED com destinação à exploração industrial de recursos minerais nos departamentos amazônicos e mesmo em outros biomas/regiões do país. Desde o governo Uribe (2002-2006 e 2006-2010) o governo colombiano têm buscado intensificar a atração de IED com desregulamentação e incentivos fiscais e, ao mesmo tempo, combatendo com maior intensidade as guerrilhas, ampliando sua presença no território colombiano com o fim de assegurar segurança aos investidores estrangeiros. 
o extrativismo, arraigado na história latino americana, voltava forte como "motor" do pretenso desenvolvimento na região.

O IED impacta de maneira assertiva seja na consolidação ou na diversificação dos perfis produtivos, tanto que para o ano de 2012 a América Latina (incluindo o Caribe, mas com menor peso relativo) captou fluxos de IED na monta de 3\% do produto interno bruto (CEPAL, 2015). Esse crescimento relativo, quando percebemos a trajetória de IED na região, deve-se muito a consolidação das empresas transnacionais na região, especialmente em setores intensivos de capital. É importante reforçar que esse cenário de consolidação do IED na região deveu-se, em grande medida, ao boom do preço das commodities entre 2000 e 2012. No Gráfico 1 é possível visualizar um retrato desse crescimento, destacando-se os casos do Brasil e do Chile, grandes exportadores de commodities minerais.

Em 2010, por exemplo, enquanto o Peru atingiu as cifras de US\$ 7,3 bilhões, o México atingia as cifras de US\$17,7 bilhões perfazendo um diferencial substancial entre os países. Um fator diferencial, no que diz respeito ao IED, entre os países foram os mais de 90\% de IED (de procedência chinesa) destinados à extração de recursos naturais, atingindo, especialmente, o setor de mineração (em especial a extração do cobre) e exploração

Gráfico 1. América Latina e Caribe (países selecionados): entrada de investimento estrangeiro direto (Em milhões de dólares), 2011 e 2012.

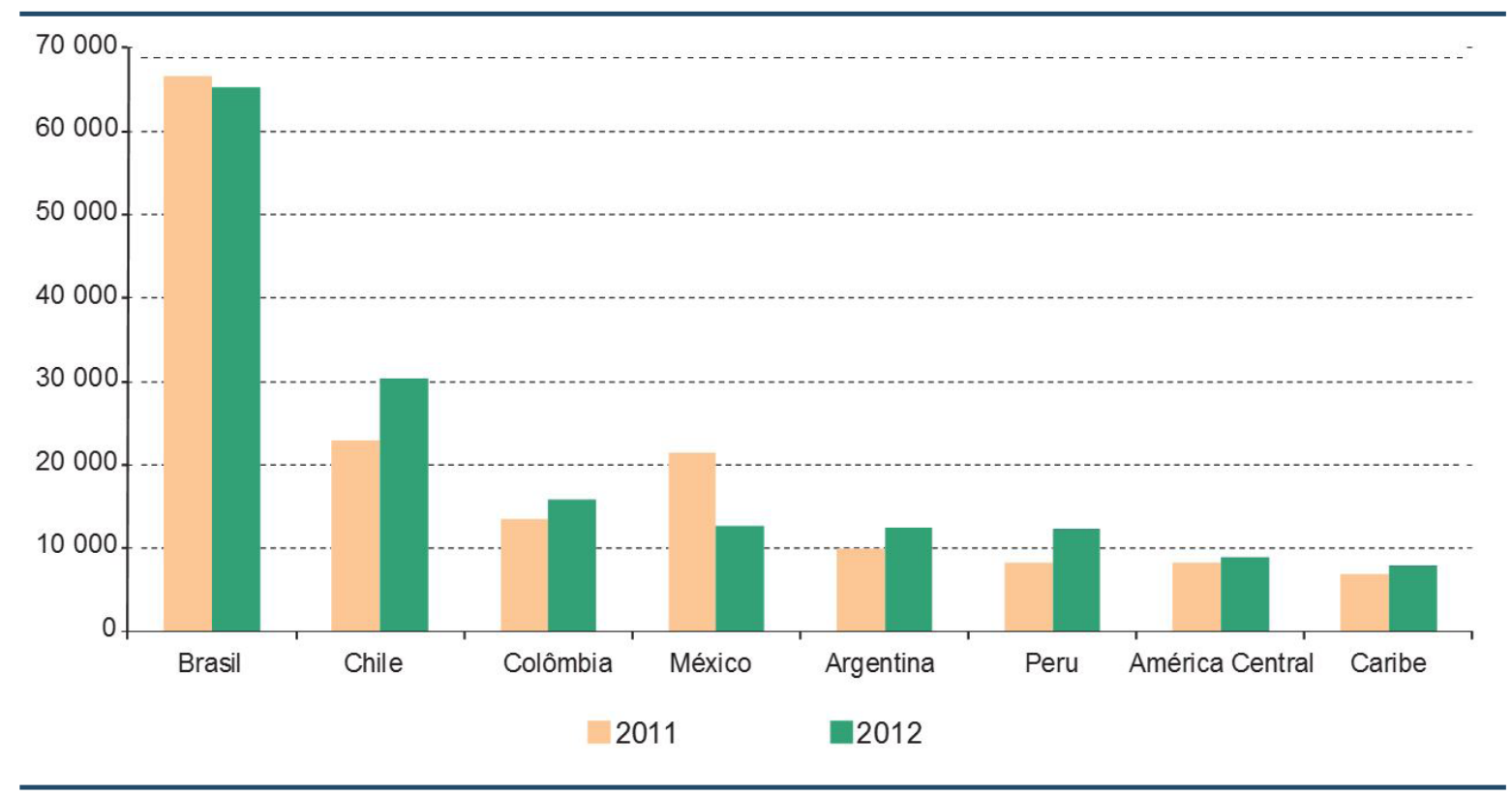

Fonte: CEPAL (2015). 
T\&P "Paraísos perdidos": investimento estrangeiro direto em mineração e conflitos ecológicos distributivos no Brasil, na Colômbia e no Peru

de recursos florestais no Peru, enquanto o México o IED foi destinado especialmente para o setor de serviços.

Na América Latina, os setores com maior recebimento em 2010 foram os de recursos naturais e os de serviços, com 43\% e 30\% de participação, respectivamente. Nesta sub-região mantém-se a elevada importância dos recursos naturais e, em comparação com 2005-2009, observou-se inclusive um aumento do peso dos setores primários nos investimentos, especialmente por parte da China (CEPAL, 2012). Por exemplo, de acordo com o relatório: "[...] mais de 90\% dos investimentos chineses confirmados na América Latina foram direcionados para a extração de recursos naturais" (CEPAL, 2012, p. 12). Há, neste sentido, uma verdadeira "corrida pelos recursos naturais" na região e a mineração, em especial, merece destaque. Por volta do início dos anos 2000, somente 0,98\% da Colômbia encontrava-se titulada em todo o seu território para fins de exploração minerária, hoje a área alcança 36\% do território colombiano (SIMCO, 2014).

O IED, neste sentido, é um ativo político estratégico na região. A premissa é simples na lógica política em comum que une governos mais à Esquerda ou Direita do espectro político: a liberalização do IED resulta no aumento nas taxas de investimento, o que leva a um maior crescimento econômico e (hipoteticamente) ao desenvolvimento na região.

A Colômbia é um dos exemplos mais ilustrativos de ambiente regulatório favorável à atração de IED para a mineração, além de fomentar políticas pouco responsivas ambientalmente. O Estado delegou à iniciativa privada a exploração de recursos minerais desde a promulgação do Código de Minas em 2001, recebendo apenas os royalties pela exploração. Do ponto de vista da gestão ambiental pública, no Decreto 1728 de 2002 (COLOMBIA, 2002), foi eliminado o requisito de licenciamento ambiental e apresentação de Estudo de Impacto Ambiental, atingindo por volta de 47\% das atividades previamente obrigadas, resultando apenas, junto à autoridade ambiental, os "guias ambientais".

Claramente, deve-se destacar, houve uma flexibilização da legislação ambiental colombiana em favor de uma maior celeridade para o investidor. Já o Decreto 1220 de 2005 (COLOMBIA, 2005b). incluiu a participação (em caráter consultivo apenas e não deliberativo) das comunidades na outorga da Licença Ambiental e na elaboração do Estudo de Impacto Ambiental, desde que os projetos ou empreendimentos afetem especificamente as comunidades indígenas ou afro-colombianas (o que termina por excluir importantes atores sociais afetados por esses empreendimentos), gerando um 
conflito normativo, pois a Colômbia é signatária da Convenção 169 da OIT3 , o que resultou em inúmeros protestos, litígios jurídicos e a necessidade de regulamentar as atividades minerárias em terras indígenas e afrodescendentes.

No caso colombiano eliminou-se todo tipo de restrições ao investimento, até mesmo abolindo-se a diferenciação entre investidores nacionais e estrangeiros, além da criação de incentivos tributários e, com a Lei 963 de 2005 (COLOMBIA, 2005a), estabeleceu-se contratos de estabilidade jurídica, no qual se aplica a projetos que superem o milhão de dólares e tenham, ao menos, uma vigência entre 3 e 20 anos.

Mesmo diante da "hipótese" entre "mais IED, maior desenvolvimento", entendemos que o IED por si só não estimula o crescimento geral da economia (e muito menos favorece níveis mais elevados de proteção ambiental e, portanto, sustentabilidade) de um determinado país, pois são necessárias políticas nacionais que em conjunto auxiliam no desenvolvimento da região. A esperança seria que o IED traria aos países uma melhora nos conhecimentos, na habilidade e na capacidade tecnológica das empresas locais, o que promoveria o desenvolvimento econômico generalizado da região. Os governos brasileiro, colombiano e peruano (entre outros) absorveram o IED como um recurso não apenas econômico para o crescimento, mas também para sua "Iocomotiva" política de desenvolvimento, associando as duas dimensões. Observação que permite retomar brevemente as considerações sobre maior extração de recursos naturais, menor impacto no crescimento econômico e desenvolvimento regional (O'FAIRCHEALLAIGH; GIBSON, 2012).

No entanto, tal liberalização econômica tem despertado preocupações, pois os resultados que podem ser observados não correspondem com as expectativas e corresponderiam ao pessimismo envolvendo a relação entre mineração e desenvolvimento. Auty e Warhust (1993) avalia que a cada ponto percentual de participação da extração de recursos naturais no PIB reduz a taxa de crescimento econômico anual da economia em 0,09\%. Trocadilho a parte, o verdadeiro "ouro de tolo".

Auty eWarhust (1993) já apontavam a intricada relação entre mineração e desenvolvimento econômico. A premissa analítica dos autores é relativamente simples: a alta lucratividade obtida pela mineração provoca uma acentuada valorização cambial e inflação salarial

3 No Artigo 7 da Convenção 169 da Organização Internacional do Trabalho assevera-se que é um direito dos povos participarem tanto na formulação quanto na implementação e avaliação dos planos e programas de desenvolvimento local, regional e nacional que venham a afeta-os diretamente (IPHAN, 2011). 
T\&P "Paraísos perdidos": investimento estrangeiro direto em mineração e conflitos ecológicos distributivos no Brasil, na Colômbia e no Peru

entre os mineiros (ainda que essa máxima precisa ser refletida detidamente para os casos de economias em desenvolvimento) e uma externalidade para a diversificação da cadeia produtiva, desindustrializando sua economia.

Ainda que autores como Gavin Wright (2001) apontem que seja possível estratégias de desenvolvimento amparadas na exploração de recursos naturais, o desenvolvimento só será possível se paralelamente houver significativos investimentos em educação e alta tecnologia. E, acrescento, com instituições políticas consolidadas previamente a descoberta e exploração dos minerais para a regulação das atividades extrativistas.

Ao mesmo tempo em que existe um debate econômico centrado na "maldição dos recursos naturais" e o sufocamento do desenvolvimento do setor produtivo, há também uma contraparte sobre o impacto da abundância de recursos naturais nos arranjos político-institucionais locais. Ades e Di Tella (1999) apontam que a abundância de recursos naturais termina por se tornar um incentivo a uma gestão pública ineficiente, além de propensa ao clientelismo bem como a corrupção.

Desta forma, unidades políticas que dependem fortemente de commodities como minérios para seu crescimento econômico padeceriam de um "paradoxo da abundância", ou seja, a exploração das commodities não levaria, nem a médio e longo prazo, ao desenvolvimento desse país ou região, também não promoveriam a consolidação das instituições, quando não as "implodiria" numa rede de clientelismo e corrupção justamente por se não encontrarem completamente institucionalizadas. E, acrescento, o extrativismo minerário promove passivos ambientais ${ }^{4}$ sumariamente não contabilizados no conjunto de políticas destinadas a atração de IED para exploração de recursos naturais, além de conflitos ecológicos distributivos nas regiões onde operam as mineradoras.

\section{Mineradoras Transnacionais no Brasil, na Colômbia e no Peru: royalties, impactos ambientais e conflitos}

Como já observado, nos últimos dez anos houve um boom no preço das commodities, especialmente por minérios como ouro, ferro, bauxita, cobre, entre outros minerais, o que impulsionou, muitas vezes de maneira legal e ilegal uma desenfreada e com alto

4 Entendemos passivo ambiental de forma associada e complementar ao conceito de dívida ecológica, ou seja, passivo ambiental é a soma dos danos não compensados produzidos por uma empresa no meio ambiente ao longo da sua trajetória de atividade, incluindo danos por acidente. 
impacto social e ambiental exploração desses minerais em larga escala tanto no Brasil quanto na Colômbia e no Peru.

A argumentação em torno do fomento de políticas de atração de IED gira em torno de uma premissa: sua liberalização resulta no aumento nas taxas de investimento, o que leva a um maior crescimento econômico (CEPAL, 2012). Neste sentido, o Investimento Estrangeiro Direto destinado ao extrativismo mineiro é considerado um recurso político fundamental para o desenvolvimento econômico, mas que, do ponto de vista da baixa regulação ambiental e controle democrático, também pode ser considerado, por estes dois fatores, oneroso para a qualidade ambiental de países em desenvolvimento. Outro ponto a ser observado especialmente no setor de mineração (incluindo aí petróleo e gás natural), é que para cada 2 milhões de dólares em investimento cria-se apenas um posto de trabalho (MORALES, 2012).

De acordo com a CEPAL (2012), boa parte do IED do Brasil, da Colômbia e do Peru nos últimos anos foi direcionado a projetos de exploração de recursos naturais do quais a mineração foi um dos setores de maior expressividade econômica, mesmo que setores econômicos ligados a exploração de commodities afirmem haver uma elevada morosidade no licenciamento ambiental, especialmente no caso brasileiro e (até recentemente) colombiano, diante do peruano com menor regulamentação ambiental. O que termina por fomentar, de um lado, um ambiente econômico favorável ao IED e menos atento aos passivos ambientais em países como os latino americanos e, do outro, um setor dependente de investimento público para gerar infra-estrutura (como portos e estradas) para atender o escoamento da extração mineral, aém de um comportamento predatório de empresas transnacionais ligadas a exploração de commodities "livres" de "amarras" jurídicas ambientalmente mais responsivas de seus países de origem, em geral desenvolvidos.

Outra crítica apontada pela literatura especializada é a de que mesmo que um país com abundância de commodities detenha políticas de redistribuição dos royalties entre suas entidades (departamentos ou estados e municípios) as mesmas não influenciarão, necessariamente, em melhores indicadores sociais e muito menos ambientais. Ainda que o montante de IED destinado à região tenha sido significativo, bem como seu caráter exponencial, é possível observar que não apenas a tributação sobre a exploração 
mineral é diversificada na América Latina, mas também que a redistribuição dos ganhos é limitada, como é possível observar no Quadro 1.

No Quadro 1, ao compararmos uma seleção de países latino americanos, os impostos sobre a renda mineira são similares, com o Brasil atingindo taxas de 34\%, o Peru taxas de 30\% e a Colômbia taxas de 33\%, diferenciando-se especialmente o Chile com apenas 17\%. Outro ponto que deve ser destacado é o da participação nos lucros da exploração mineral, destacando-se apenas o México com 10\% e o Peru com 8\%, enquanto o Brasil e a Colômbia essa participação não é regulamentada nos países.

Na Colômbia, por exemplo, o novo marco normativo da mineração criou um fundo que distribuiu os recursos oriundos dos royalties da mineração e extração de petróleo e gás repartindo entre o Fondo de Ciencia, Tecnologia e Innovación (10\%), uma poupança pensional territorial (10\%) e até 30\% para o Fondo de Ahorro y Estabilización. Os restantes dos recursos, de acordo com dados do DNP (2009), distribuem-se em 20\% para regiões produtoras e 80\% para os "Fondos de Compensación Regional y de Desarrollo Regional" (Acto Legislativo 05 de 2011, COLOMBIA, 2011b).

Quanto ao caso peruano, na discriminação da distribuição de royalties oriundos da exploração de recursos naturais, dos 50\% dos impostos (na renda) que as empresas pagam para a exploração de recursos minerários, $10 \%$ são destinados para os municípios do distrito produtor, 25\% para os municípios da província produtora, 40\% para os municípios do departamento produtor e 25\% para o governo regional, dos quais 20\% devem ser destinados a uma universidade pública. Já para o caso brasileiro, a Lei no 7.990, de 28/12/1989 (BRASIL, 1989). instituiu a compensação financeira de até 3\% sobre o valor do faturamento líquido oriundo da venda do minério, após a última etapa do processo de beneficiamento e processamento industrial (constituindo uma espécie de royalty ad valorem), dos quais a receita é compartida em 12\% para órgãos da União (aí incluídos o DNPM, o IBAMA, o ICMBio, o MCT\&l), 23\% para o Estado de onde se extraiu o mineral e 65\% para o município do qual foi extraído o mineral.

É importante frisar que há uma acentuada concentração espacial dos royalties da mineração tanto na Colômbia quanto no Peru. Na Colômbia, entre 1994 (antes do boom do preço das commodities) e 2005 (já sob o boom do preço das commodities) quase 60\% dos royalties ficaram concentrados em cinco departamentos: Casanare (21,5\%), Arauca (10,9\%), Meta (9\%), Huila (7,7\%) y La Guajira (7,3\%). No Peru repete-se o mesmo padrão 


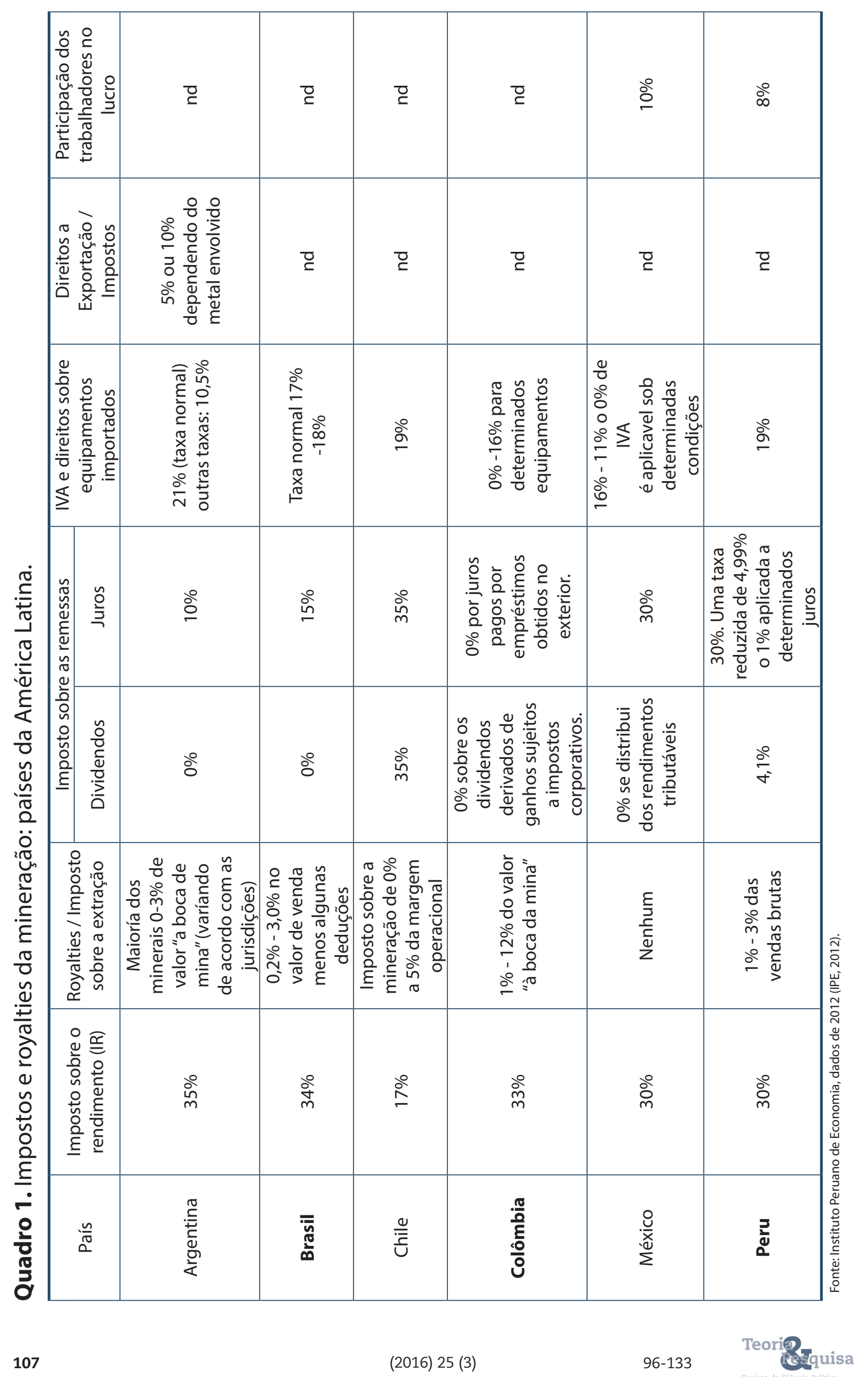


T\&P "Paraísos perdidos": investimento estrangeiro direto em mineração e conflitos ecológicos distributivos no Brasil, na Colômbia e no Peru

de concentração com a concentração de $85 \%$ dos royalties em sete departamentos: Ancash, Arequipa, Moquegua, La Libertad, Tacna, Puno e Cajamarca. O resultado dessa alta concentração é o alto grau de dependência dessa renda por parte dos departamentos, veja-se o caso de Casanare e Arauca que atingem 58\% e 48\% (BENAVIDES et al., 2000). De acordo com Ana Carolina González Espinosa (2013) no Peru, por exemplo, os royalties derivados da exploração de recursos naturais representam 97\% dos investimentos dos departamentos de Tacna, 95\% de Pasco, 85\% de Moquegua e Ancash e 80\% de Cusco.

Arellanos (2008) aponta que nas áreas rurais da Amazônia peruana, onde muitas companhias transnacionais operam na explotação mineira, a pobreza é estimada em 62\%. O Instituto Nacional de Estadística e Informática do Peru (INEI, 2007, p. 9-10) informa que os departamentos peruanos mais ricos em recursos naturais são exatamente aqueles que se encontram no maior nível de pobreza, atingindo em Loreto a taxa de 66\% e 66\% em Cajamara.

Benavides et al. (2000) estimou a influência nula dos royalties do IED no crescimento econômico das regiões colombianas, especialmente em curto prazo. Ao analisar os dados disponíveis pelo Departamento Nacional de Planeación ${ }^{5}$, foi percebido que a maioria dos municípios e departamentos colombianos que recebem royalties ainda não cumprem com as metas de cobertura mínima em indicadores como mortalidade infantil, educação e saneamento básico. Em 2006, já sob efeito do boom dos preços de commodities minerárias, das 710 unidades administrativas no território colombiano, apenas 07 haviam cumprido a cobertura mínima, inclusive 550 delas teriam taxas de mortalidade infantil superiores a 25 por mil e, especificamente, 26 municípios colombianos teriam, no mesmo indicador, taxas superiores a 50 por mil.

Entre os Estados que tomam parte do bioma amazônico brasileiro, o Pará é o maior exportador de minérios e arrecadou em royalties, apenas em 2007, a soma de $\mathrm{R} \$ 149.361 .584,52$ e o montante de recursos distribuídos entre os municípios mineradores foi de $\mathrm{R} \$ 96.590 .159,74$, dos quais apenas cinco destes concentram 97,58\% dos recursos. Em 2007, por exemplo, Parauapebas foi contemplada com R\$ 55.141.077,33, o equivalente a 57,09\% dos recursos; Oriximiná, 20,06\%; Canaã dos Carajás, 16,19\%; Ipixuna do Pará, 3,12\%; e Paragominas, 1,12\%. Embora um montante significativo, sua distribuição não equitativa das divisas entre os municípios (ainda assim) refletiu em melhoras do IDH-M

5 Para consulta dos dados, acessar DNP (2015). 
em todos os municípios selecionados também de maneira desigual. Parauapebas deteve a melhor série temporal de IDH-M, mas todos obtiveram um salto significativo do índice entre 2001 e 2010, como é possível determinar pela Tabela 1.

Dados da CEPAL (2012) apontam que em 2007, antes de estourar a crise financeira internacional, a indústria de mineração no Brasil (tanto a extrativa quanto a de transformação mineral) contribuiu com 5\% do Produto Interno Bruto brasileiro, por volta de US\$ 65 bilhões num montante total de US\$1,3 trilhão. Em 2008, por exemplo, a mineração brasileira atingiu uma soma de US\$23,95 bilhões, algo em torno de 2\% do PIB brasileiro.

Não é de se estranhar que o Brasil sendo um grande receptador de IED destinado ao extrativismo minerário ocorra, consequentemente, uma pressão política por maior celeridade no licenciamento ambiental em mineração, como indica a leitura do Plano Nacional de Mineração 2030. Outro exemplo de país com alta receptividade ao IED em mineração, o Peru, por exemplo, por meio do Decreto Supremo Nº60-2013-PCM (PERU, 2013) ${ }^{6}$ determinou que os Estudos de Impacto Ambiental (EIA) deveriam ser aprovados em menos de cem dias, medida que potencializa ainda mais impactos ambientais e conflitos ecológicos distributivos no país.

Ainda que o discurso do desenvolvimento soe atrativo tanto aos tomadores de decisão quanto aos membros das comunidades que receberão o empreendimento minerário, um caso ilustrativo do risco (e, neste caso, consequente desastre) ambiental promovido pela mineração na Amazônia brasileira foi nos municípios de Oriximiná/ Juruti no Estado do Pará, envolvendo a ALCOA (em consórcio com a BHP Billinton e a Alumar) e antes dela, a Mineração Rio do Norte (MRN) desde 1976, especificamente na unidade de conservação (UC) Flona Saracá-Taquera (ALCOA, 2004). A crônica de um desastre, definitivamente, era anunciada, já que por volta de 25\% da UC está tomada de processos minerários ativos desde antes da criação da própria UC (concessão de lavra, autorização de pesquisa e requerimento de lavra) como é possível visualizar na Figura 1.

Uma das características da Flona de Saracá-Taquera é a superposição existente entre a unidade de conservação e terras quilombolas. E dado que a Flona de Saracá-Taquera tem por volta de 25\% de sua área licenciada para mineração, o efeito associado imediato foi o mesmo ocorrer com as terras quilombolas, como é possível identificar na Tabela 2.

6 Para maiores informações sobre o Decreto, consultar Peru (2013). 
T\&P "Paraísos perdidos": investimento estrangeiro direto em mineração e conflitos ecológicos distributivos no

Tabela 1. Índice de Desenvolvimento Humano - Municípios - série temporal.

\begin{tabular}{lcll}
\hline & IDH-M & IDH-M & IDH-M \\
\cline { 2 - 4 } & $\mathbf{1 9 9 1}$ & $\mathbf{2 0 0 0}$ & $\mathbf{2 0 1 0}$ \\
\hline Brasil & 0,493 & 0,612 & 0,727 \\
\hline Canaã dos Carajás (PA) & 0,276 & 0,456 & 0,673 \\
\hline Ipixuna do Pará (PA) & 0,268 & 0,317 & 0,489 \\
\hline Oriximiná (PA) & 0,390 & 0,517 & 0,623 \\
\hline Paragomimas (PA) & 0,336 & 0,471 & 0,645 \\
\hline Parauapebas (PA) & 0,439 & 0,553 & 0,715 \\
\hline
\end{tabular}

Fonte: Atlas do Desenvolvimento Humano no Brasil (2014).

Tabela 2. Processos minerários em terras quilombolas no Baixo Amazonas.

\begin{tabular}{lccc}
\hline \multicolumn{1}{c}{ Terra Quilombola } & $\begin{array}{c}\text { Número de Processos } \\
\text { Minerários }\end{array}$ & $\begin{array}{c}\text { Área dos Processos } \\
\text { (há) }\end{array}$ & $\begin{array}{c}\text { \% frente à dimensão } \\
\text { total da TQ }\end{array}$ \\
\hline Água Fria & 3 & 403,20 & $72,4 \%$ \\
\hline Alto Trombetas & 9 & $7.858,07$ & $3,7 \%$ \\
\hline Ariramba & 9 & $17.692,96$ & $75,6 \%$ \\
\hline Erepecuru & 48 & $140.093,94$ & $64,3 \%$ \\
\hline Jamari/ Último Quilombo & 7 & $12.002,26$ & $8,6 \%$ \\
\hline Trombetas & 18 & $62.264,58$ & $77,0 \%$ \\
\hline
\end{tabular}

Fonte: DNPM (2015).

Figura 1. Incidência de Processos Minerários na Flona Saracá-Taquera e Reserva Biológica Rio Trombetas.

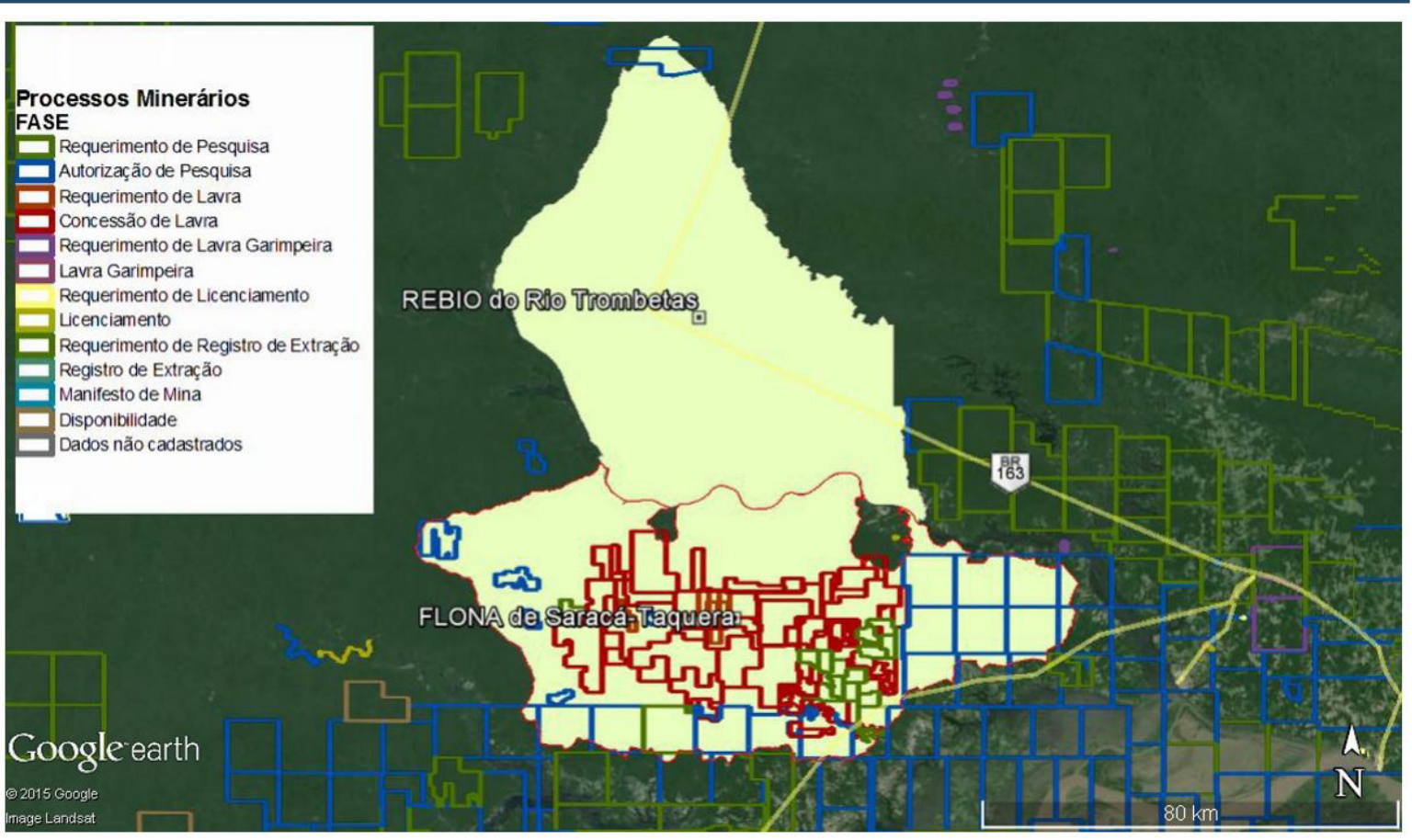

Fonte: DNPM (2015), ICMBIO (2001). Fonte: Imagem de satélite tomada via Google Earth (2015). Consulta em Setembro de 2015. 
A incidência de processos minerários, embora reduzidos em algumas terras quilombolas (3 processos, por exemplo em Água Fria, totalizam 72,4\% do território), são altamente impactantes em sua magnitude e alcance. Essa afirmação deriva dos procedimentos para a extração da bauxita (a camada de bauxita chega a 10 metros de profundidade no local) quanto o transporte e destinação em Juruti (FIOCRUZ, 2009).

Para situar alguns dos impactos ambientais da extração da bauxita, são necessárias por volta de quatro a cinco toneladas do minério para se extrair uma tonelada de metal. Como um dos efeitos perversos, a emissões do alumínio, altamente tóxicas na atmosfera, terminam por afeta a vegetação, a biodiversidade local e a população humana (LIMA; MOTA, 2009).

O caso de desastre ambiental se deu nas águas do Lago do Batata com seu assoreamento e contaminação com rejeito da bauxita, atingindo diretamente comunidades quilombolas que dependiam para sua subsistência e comércio recursos aquíferos do rio Trombetas. Entre 1979 e 1989, foram lançados pela MRN no lago Batata o rejeito da lavagem de bauxita (argila) nesse ecossistema, o que terminou por provocar o assoreamento de aproximadamente 30\% do lago (ICMBIO, 2001). Não é de se surpreender a magnitude desse impacto no lago Batata, pois do ponto de vista ambiental, a produção de alumínio primário consome muita energia, exaure recursos e produz rejeitos significativos que impactaram diretamente as populações quilombolas e ribeirinhas, bem com os bens e serviços ambientais que sustentam a economia local.

É ilustrativo que a elaboração do Estudo de Impacto Ambiental/Relatório de Impacto Ambiental (EIA/RIMA) já prenunciasse um conflito ecológico distributivo. Em reportagem no local, a agência de notícias Pública entrevistou um líder comunitário local sobre as relações da mineradora e as comunidades locais:

Quando a Alcoa apareceu aqui, em 2000, ela veio como os portugueses 500 anos atrás, distribuindo muitos presentes nas 49 comunidades, conta Gerdeonor Pereira. A empresa visitou todas elas, dizendo que o progresso e o desenvolvimento estavam chegando para o município e para a região de Juruti Velho. Ela fazia reuniões nas comunidades e depois distribuía camiseta, sandália, garrafa térmica, bicicleta, recorda o presidente da Acorjuve. [...] Simplesmente, 49 comunidades e 9 mil pessoas não existiam para a empresa. Fomos completamente ignorados, afirma Gerdeonor?

7 Para leitura da matéria acesse Barros (2012). 
T\&P "Paraísos perdidos": investimento estrangeiro direto em mineração e conflitos ecológicos distributivos no Brasil, na Colômbia e no Peru

O cenário ainda se deteriorou quando o EIA/RIMA ficou pronto e a ausência dos impactos nas comunidades era inexistente (e, consequentemente, compensações), como atesta a fala de Gerdeonor Pereira, o que terminou por envolver o Ministério Público Federal e Estadual no conflito entre a ALCOA e as comunidades atingidas ${ }^{8}$. Assim como no caso do licenciamento ambiental na Cerro Matoso na Colômbia com as licenças de exploração no 18.065, no 025-23 e nº 026-23 em que se apontava a não existência de comunidades (sejam indígenas ou afrodescendentes) na área licenciada, assim também se deu com o caso da Alcoa em Juruti Velho e comunidades no seu entorno, no Pará. De acordo com Luis J. M. Wanderley (2009, p. 484):

O interesse da ALCOA, no início dos anos de 1990, no Trombetas provocou fortes mobilizações dos quilombolas [...]. Durante o licenciamento e a audiência pública, em 1991, os negros demonstraram sua recusa e resistência à proposta de desenvolvimento regional. O temor de se repetirem as relações de subserviência e a dependência existente em Boa Vista, os perigos e danos ambientais às florestas, lagos e rios (caso do lago Batata) e a desordem social da região estavam entre os argumentos expressos pela então fundada Associação dos Remanescentes de Quilombo do Município de Oriximiná - ARQMO.

O processo de desterritorialização das comunidades afrodescendentes foi potencializado por avaliações de impacto dos empreendimentos minerários aquém do necessário, especialmente respeito o princípio da Convenção 169 da OIT que preza a Consulta Prévia às populações atingidas, além da inépcia do Poder Público em fiscalizar de maneira adequada os procedimentos de licenciamento ambiental.

E, com uma ajuda financeira por parte do Estado, reforce-se. Mesmo diante da publicização dos erros cometidos no EIA/RIMA do empreendimento da ALCOA em Juruti Velho no Pará, o BNDES tratou de financiar o empreendimento da mineradora transnacional em significativos montantes de recursos diretos como é possível observar por meio da visualização da Tabela 3, ainda que sua "política de responsabilidade social e ambiental" vete o financiamento de empreendimentos sem a realização do devido licenciamento ambiental (como a etapa obrigatória de Consulta Prévia às populações atingidas pelo empreendimento).

8 Para maiores informações acesse Brasil (2015). 
Tabela 3. Financiamento do BNDES para empreendimento extrativo da ALCOA em Juruti Velho - Pará.

\begin{tabular}{|c|c|c|c|c|c|}
\hline Processos e Empresas & Projetos & UF & $\begin{array}{l}\text { Datas e } \\
\text { Valores }\end{array}$ & Setor & $\begin{array}{c}\text { Ação de } \\
\text { Financiamento }\end{array}$ \\
\hline ALCOA ALUMINIO S/A & $\begin{array}{c}\text { IMPLANTACAO DE } \\
\text { INFRA-ESTRUTURA PARA } \\
\text { EXPLORACAO DE MINA DE } \\
\text { BAUXITA, COMCAPACIDADE DE } \\
\text { PRODUCAO DE 2,6 MILHOES } \\
\text { T/ANO, EM JURUTI-PA. }\end{array}$ & PA & 02/04/2009 & - & 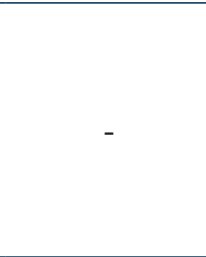 \\
\hline 23.637.697/0001-01 & & & $745.141 .568,00$ & $\begin{array}{l}\text { ÁREA DE } \\
\text { INSUMOS } \\
\text { BÁSICOS }\end{array}$ & DIRETA \\
\hline ALCOA ALUMINIO S/A & IMPLANTAÇÃO DE & & $26 / 10 / 2007$ & - & - \\
\hline 23.637.697/0001-01 & $\begin{array}{c}\text { INFRAESTRUTURA PARA } \\
\text { EXPLORAÇÃO DE MINA DE } \\
\text { BAUXITA, COM CAPACIDADE DE } \\
\text { PRODUÇÃOO DE 2,6 MILHÕES } \\
\text { T/ANO, EM JURUTI-PA. }\end{array}$ & PA & $500.000 .000,00$ & $\begin{array}{c}\text { ÁREA DE } \\
\text { INSUMOS } \\
\text { BÁSICOS }\end{array}$ & DIRETA \\
\hline
\end{tabular}

Fonte: BNDES (2015).

É uma aposta política por parte de países com alto potencial mineral em usar de seus recursos para alavancar seu desenvolvimento e essa aposta política se dá, especialmente, pela atração de grandes mineradoras para explorar os recursos minerais, ainda que o custo social e ambiental (parcial ou mesmo inexistente quanto a sua internalização) seja alto e, como já observado, muitas vezes nem contabilizado.

De acordo com Ana Carolina González Espinosa (2013, p. 105):

[...] la inversión extranjera associada a dicha explotación permitiria, según los defensores de esta tesis, cubrir el déficit de capital y proporcionar importantes reservas internacionales e ingresos para que los Estados pudieram mejorar la prestación de servicios públicos y [...] infraestructura.

De uma forma ou de outra retomamos o debate em torno da pergunta: a mineração é uma dádiva ou uma maldição? Há uma significativa distância entre receber royalties e reduzir a desigualdade social, tanto na Colômbia quanto no Peru, como é possível determinar pela variação de dados sobre desigualdade dispostos nos Quadros 2 e 3.

Mensurados por indicadores como pobreza ou desigualdade o cenário disposto pelos dados indica a não reversibilidade de benefícios diretos da mineração para as 
T\&P "Paraísos perdidos": investimento estrangeiro direto em mineração e conflitos ecológicos distributivos no Brasil, na Colômbia e no Peru

Quadro 2. Indicadores sociais nos principais departamentos mineiros na Colômbia, 2002-2011.

\begin{tabular}{|c|c|c|c|c|c|c|c|c|c|c|}
\hline & Posição & & 2002 & 2003 & 2004 & 2005 & 2008 & 2009 & 2010 & 2011 \\
\hline \multirow{3}{*}{$\begin{array}{l}\text { La } \\
\text { Guajira }\end{array}$} & 5 & Pobreza & 67,2 & 58,3 & 57,7 & 57,8 & 69,9 & 66,7 & 64,6 & 57,4 \\
\hline & 3 & $\begin{array}{l}\text { Pobreza } \\
\text { extrema }\end{array}$ & 31,1 & 20,3 & 18,3 & 22,2 & 43,9 & 35,5 & 37,6 & 28,1 \\
\hline & 2 & $\begin{array}{c}\text { Coeficiente de } \\
\text { Gini }\end{array}$ & 0,484 & 0,503 & 0,485 & 0,474 & 0,592 & 0,569 & 0,613 & 0,567 \\
\hline \multirow{3}{*}{ César } & 9 & Pobreza & 61,9 & 60,1 & 59,2 & 56,2 & 63,2 & 58,6 & 53,6 & 47,2 \\
\hline & 7 & $\begin{array}{l}\text { Pobreza } \\
\text { extrema }\end{array}$ & 19,2 & 15,0 & 17,6 & 14,9 & 30,2 & 23,8 & 18,6 & 17,2 \\
\hline & 14 & $\begin{array}{c}\text { Coeficiente de } \\
\text { Gini }\end{array}$ & 0,464 & 0,439 & 0,480 & 0,453 & 0,545 & 0,553 & 0,518 & 0,506 \\
\hline \multirow{3}{*}{ Antioquía } & 20 & Pobreza & 47,9 & 46,2 & 44,4 & 41,8 & 38,3 & 35,1 & 31,3 & 29,3 \\
\hline & 17 & $\begin{array}{l}\text { Pobreza } \\
\text { extrema }\end{array}$ & 17,8 & 15,5 & 14,7 & 13,9 & 15,4 & 12,8 & 10,5 & 8,7 \\
\hline & 7 & $\begin{array}{c}\text { Coeficiente de } \\
\text { Gini }\end{array}$ & 0,585 & 0,589 & 0,574 & 0,555 & 0,580 & 0,560 & 0,561 & 0,537 \\
\hline \multirow{3}{*}{ Córdoba } & 3 & Pobreza & 65,6 & 64,0 & 67,6 & 63,7 & 62,0 & 61,8 & 63,6 & 61,5 \\
\hline & 4 & $\begin{array}{l}\text { Pobreza } \\
\text { extrema }\end{array}$ & 31,6 & 32,4 & 31,9 & 28,1 & 23,9 & 25,0 & 25,6 & 27,0 \\
\hline & 3 & $\begin{array}{c}\text { Coeficiente de } \\
\text { Gini }\end{array}$ & 0,552 & 0,554 & 0,529 & 0,540 & 0,524 & 0,558 & 0,550 & 0,556 \\
\hline \multirow{3}{*}{ El Chocó } & 1 & Pobreza & 67,6 & 69,2 & 72,7 & 74,7 & 73,1 & 68,3 & 64,9 & 64,0 \\
\hline & 2 & $\begin{array}{l}\text { Pobreza } \\
\text { extrema }\end{array}$ & 32,4 & 36,2 & 41,6 & 44,2 & 45,9 & 40,5 & 33,5 & 34,3 \\
\hline & 1 & $\begin{array}{c}\text { Coeficiente de } \\
\text { Gini }\end{array}$ & 0,572 & 0,562 & 0,562 & 0,582 & 0,619 & 0,571 & 0,571 & 0,567 \\
\hline \multirow{3}{*}{ Boyacá } & 15 & Pobreza & 67,1 & 64,6 & 63,6 & 58,3 & 58,0 & 48,0 & 47,1 & 39,9 \\
\hline & 11 & $\begin{array}{l}\text { Pobreza } \\
\text { extrema }\end{array}$ & 39,2 & 36,4 & 33,0 & 27,4 & 31,4 & 20,0 & 19,2 & 13,4 \\
\hline & 6 & $\begin{array}{c}\text { Coeficiente de } \\
\text { Gini }\end{array}$ & 0,597 & 0,600 & 0,555 & 0,561 & 0,579 & 0,538 & 0,538 & 0,538 \\
\hline \multirow[b]{2}{*}{ Bolivar } & 10 & Pobreza & 64,9 & 53,9 & 54,8 & 51,9 & 58,3 & 57,1 & 49,4 & 43,7 \\
\hline & 12 & $\begin{array}{l}\text { Pobreza } \\
\text { extrema }\end{array}$ & 29,8 & 13,3 & 14,2 & 12,3 & 25,6 & 22,3 & 14,9 & 12,0 \\
\hline \multirow{4}{*}{$\begin{array}{c}\text { Total } \\
\text { nacional }\end{array}$} & 18 & $\begin{array}{c}\text { Coeficiente de } \\
\text { Gini }\end{array}$ & 0,533 & 0,476 & 0,478 & 0,482 & 0,543 & 0,533 & 0,514 & 0,500 \\
\hline & \multicolumn{2}{|c|}{ Pobreza } & 49,7 & 48,0 & 47,4 & 45,0 & 42,0 & 40,3 & 37,2 & 34,1 \\
\hline & \multicolumn{2}{|c|}{ Pobreza extrema } & 17,7 & 15,7 & 14,8 & 13,8 & 16,4 & 14,4 & 12,3 & 10,6 \\
\hline & \multicolumn{2}{|c|}{ Coeficiente de Gini } & 0,572 & 0,554 & 0,558 & 0,557 & 0,567 & 0,557 & 0,560 & 0,548 \\
\hline
\end{tabular}

Fonte: Elaborado a partir dos dados coletados no DNP (2015).

comunidades que sofrem os impactos diretos e indiretos da atividade econômica, embora a entrada de IED seja alta e contínua.

De acordo com os dados do Cadastro Mineiro disponibilizado pelo governo colombiano, até 2012 por volta de 6,02\% dos territórios afrocolombianos contam com títulos de mineração e 16,50\% encontram-se sob solicitação junto da Autoridad 
Quadro 3. Indicadores sociais nos principais departamentos mineiros no Peru, 2002-2010.

\begin{tabular}{|c|c|c|c|c|c|c|c|c|c|c|c|}
\hline & Posiçâo & & 2002 & 2003 & 2004 & 2005 & 2006 & 2007 & 2008 & 2009 & 2010 \\
\hline \multirow[b]{2}{*}{ Cajamarca } & 9 & Pobreza & 76,8 & 73,1 & 66,2 & 68,8 & 63,8 & 64,5 & 53,4 & 56,0 & 49,1 \\
\hline & 6 & $\begin{array}{l}\text { Extrema } \\
\text { pobreza }\end{array}$ & 18,5 & 14,5 & 10,5 & 10,6 & 10,4 & 10,7 & 7,6 & 7,6 & 6,5 \\
\hline \multirow[b]{2}{*}{ Ayacucho } & 5 & Pobreza & 72,7 & 72,9 & 65,9 & 77,3 & 78,5 & 68,3 & 64,8 & 62,6 & 55,9 \\
\hline & 3 & $\begin{array}{l}\text { Extrema } \\
\text { pobreza }\end{array}$ & 16,6 & 14,3 & 10,3 & 13,8 & 15,4 & 13,8 & 11,1 & 8,6 & 8,1 \\
\hline \multirow[b]{2}{*}{ Pasco } & 10 & Pobreza & 65,6 & 54,5 & 65,7 & 72,9 & 71,2 & 63,4 & 64,3 & 55,4 & 43,6 \\
\hline & 7 & $\begin{array}{l}\text { Extrema } \\
\text { pobreza }\end{array}$ & 14,1 & 9,3 & 11,0 & 14,6 & 13,7 & 13,1 & 12,2 & 8,5 & 4,8 \\
\hline \multirow[b]{2}{*}{ Junín } & 14 & Pobreza & 62,6 & 58,3 & 49,6 & 56,0 & 49,9 & 43,0 & 38,9 & 34,3 & 32,5 \\
\hline & 11 & $\begin{array}{l}\text { Extrema } \\
\text { pobreza }\end{array}$ & 11,4 & 8,4 & 6,2 & 7,7 & 6,3 & 5,5 & 5,5 & 3,4 & 2,9 \\
\hline \multirow{2}{*}{$\begin{array}{c}\text { La } \\
\text { Libertad }\end{array}$} & 13 & Pobreza & 50,1 & 50,4 & 48,5 & 43,0 & 46,5 & 37,3 & 36,7 & 38,9 & 32,6 \\
\hline & 8 & $\begin{array}{l}\text { Extrema } \\
\text { pobreza }\end{array}$ & 10,1 & 9,0 & 8,3 & 7,4 & 7,7 & 5,1 & 6,0 & 5,0 & 4,5 \\
\hline \multirow[b]{2}{*}{ Ancash } & 16 & Pobreza & 55,5 & 58,6 & 53,3 & 48,4 & 42,0 & 42,6 & 38,4 & 31,5 & 29,0 \\
\hline & 13 & $\begin{array}{l}\text { Extrema } \\
\text { pobreza }\end{array}$ & 8,9 & 12,6 & 8,4 & 8,6 & 6,9 & 6,1 & 4,4 & 2,9 & 2,1 \\
\hline \multirow[b]{2}{*}{ Ica } & 23 & Pobreza & 42,6 & 29,0 & 27,3 & 23,9 & 23,8 & 15,1 & 17,3 & 13,7 & 11,6 \\
\hline & 20 & $\begin{array}{l}\text { Extrema } \\
\text { pobreza }\end{array}$ & 4,7 & 2,1 & 2,2 & 1,4 & 1,4 & 0,7 & 0,8 & 0,4 & 0,4 \\
\hline \multirow[b]{2}{*}{ Arequipa } & 19 & Pobreza & 39,3 & 38,9 & 34,2 & 24,9 & 26,2 & 23,8 & 19,5 & 21,0 & 19,6 \\
\hline & 14 & $\begin{array}{l}\text { Extrema } \\
\text { pobreza }\end{array}$ & 5,4 & 5,3 & 3,4 & 2,4 & 2,3 & 2,1 & 1,7 & 1,8 & 1,7 \\
\hline \multirow[b]{2}{*}{ Moquegua } & 20 & Pobreza & 35,8 & 33,1 & 38,7 & 30,3 & 27,3 & 25,8 & 30,2 & 19,3 & 15,7 \\
\hline & 16 & $\begin{array}{l}\text { Extrema } \\
\text { pobreza }\end{array}$ & 5,5 & 3,4 & 5,5 & 3,1 & 2,6 & 2,6 & 3,4 & 1,4 & 1,3 \\
\hline \multirow[b]{2}{*}{ Lima } & 22 & Pobreza & 35,8 & 34,6 & 32,2 & 32,9 & 25,1 & 19,4 & 18,3 & 15,3 & 13,5 \\
\hline & 18 & $\begin{array}{l}\text { Extrema } \\
\text { pobreza }\end{array}$ & 3,8 & 3,4 & 2,9 & 3,1 & 2,0 & 1,3 & 1,2 & 1,0 & 0,8 \\
\hline \multirow[b]{2}{*}{ Tacna } & 21 & Pobreza & 32,0 & 32,7 & 24,7 & 30,3 & 19,8 & 20,4 & 16,5 & 17,5 & 14,0 \\
\hline & 16 & $\begin{array}{l}\text { Extrema } \\
\text { pobreza }\end{array}$ & 3,1 & 4,8 & 2,1 & 2,5 & 1,8 & 2,5 & 1,0 & 1,1 & 1,3 \\
\hline \multirow[b]{2}{*}{ TOTAL } & & Pobreza & 54,3 & 52,3 & 48,6 & 48,7 & 44,5 & 39,3 & 36,2 & 34,8 & 31,3 \\
\hline & & $\begin{array}{l}\text { Extrema } \\
\text { pobreza }\end{array}$ & 10,4 & 9,1 & 7,4 & 7,6 & 7,0 & 5,8 & 4,8 & 4,3 & 3,5 \\
\hline
\end{tabular}

Fonte: Dados coletados no INEI (2007).

Nacional de Licencias Ambientales (ANLA, 2015) para o desenvolvimento de atividades de mineração?

O investimento político por parte do governo colombiano em atrair IED em detrimento da Convenção 169 da OIT é tão significativo que entre 1994 e 2009, período da denominada "segurança democrática" nomeada pela Administração Uribe, apenas 
T\&P "Paraísos perdidos": investimento estrangeiro direto em mineração e conflitos ecológicos distributivos no Brasil, na Colômbia e no Peru

121 Consultas Prévias foram realizadas num cenário de cerca de 40\% do território titulado para exploração de riquezas minerais, ainda que muitas dessas 121 Consultas Prévias tenham sido suspensas, como as que atingiram os povos Kamëntsá, Biyá e Inga nos Departamentos de Nariño, Putumayo y Cauca, porção sudoeste amazônica colombiana. Quando observamos a porção oriental amazónica colombiana, percebemos a alta incidencia de solicitações de exploração minerária, ainda que a proporção de títulos concedidos seja consideravelmente menor nos Departamentos de Guainia, Vichada, Guaviare e Vaupés como pode ser visualizado na Figura 2.

Não é de se estranhar, portanto, o salto existente do número de conflitos ecológicos distributivos envolvendo a mineração e petróleo na Colômbia. Em 2001 foram contabilizados 10 conflitos, enquanto em 2011 ocorreram 61 conflitos contabilizados (DEFENSORIA DEL PUEBLO, 2015). É importante reforçar esse aspecto de associação entre a mineração de grande porte e os conflitos ecológicos distributivos potencializados na Colômbia. É importante reforçar que as comunidades indígenas colombianas possuem autonomia para a exploração minerária em seus territórios. No artigo 330 da Constituição

Figura 2. Títulos e solicitações minerárias no Oriente Amazônico Colombiano.

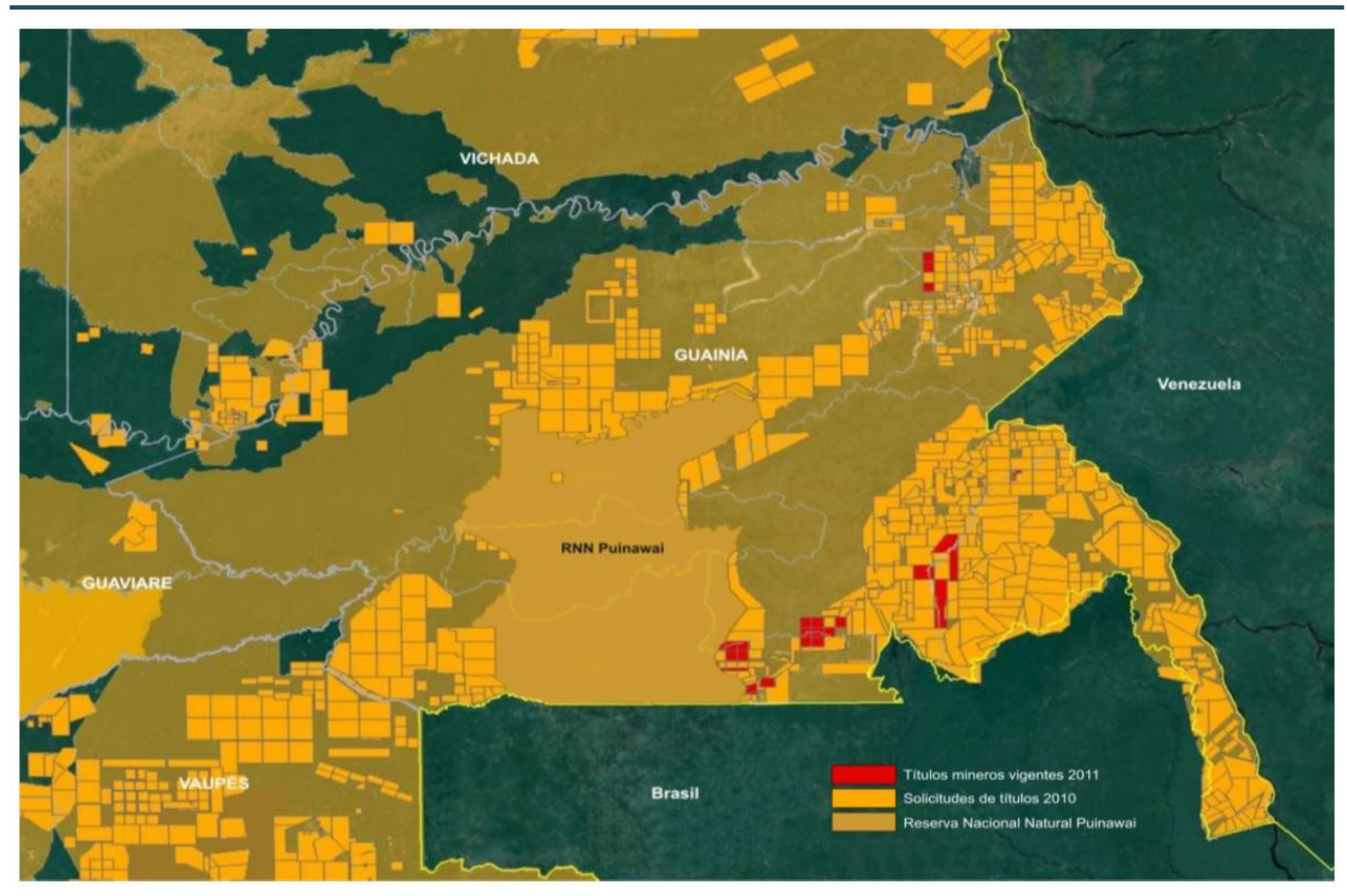

Fonte: Colombia (2014). Imagem de satélite tomada via Google Earth (2014). Consulta em Novembro de 2014. 
de 1991, foi outorgado um mandato direto às autoridades indígenas para que gestem a preservação dos recursos naturais em seus territórios. Foi no Decreto Lei 2655 de 1988 (RETTBERG; ORTIZ-RIOMALO; YAÑEZ-QUINTERO, 2014), anterior mesmo ao Código de Minas e regulamentada por meio do Decreto 710 de 1990 que criou a figura jurídica da Zona Mineira Indígena. No Código de Minas, em seu artigo 124, foi estabelecido o direito de exploração minerária pelas comunidades indígenas, ato regulamentado pela Lei 685 de 2001, em seu Artigo 122 (RETTBERG; ORTIZ-RIOMALO; YAÑEZ-QUINTERO, 2014).

De toda forma, ainda que comporte-se uma mudança institucional envolvendo regras de gestão coletiva de bens ambientais, como os minerais, mais "favoráveis" às populações indígenas, definitivamente, temos um cenário de aposta na extração de recursos naturais, uma aposta política que envolve, inclusive, operações juridicamente questionáveis (além de eticamente questionáveis), como atesta o caso da Cosigo Resources no Parque Nacional Natural na reserva indígena de Yaigojé Apaporis na Amazônia colombiana, área indígena superposta ao parque natural cercada por interesses minerários colombianos e brasileiros como pode ser visualizado na Figura 3.

Figura 3. Parque Natural Yaigoje Apaporis na Colômbia. Na porção brasileira do bioma amazônico, dezenas de requerimentos de pesquisa minerária.

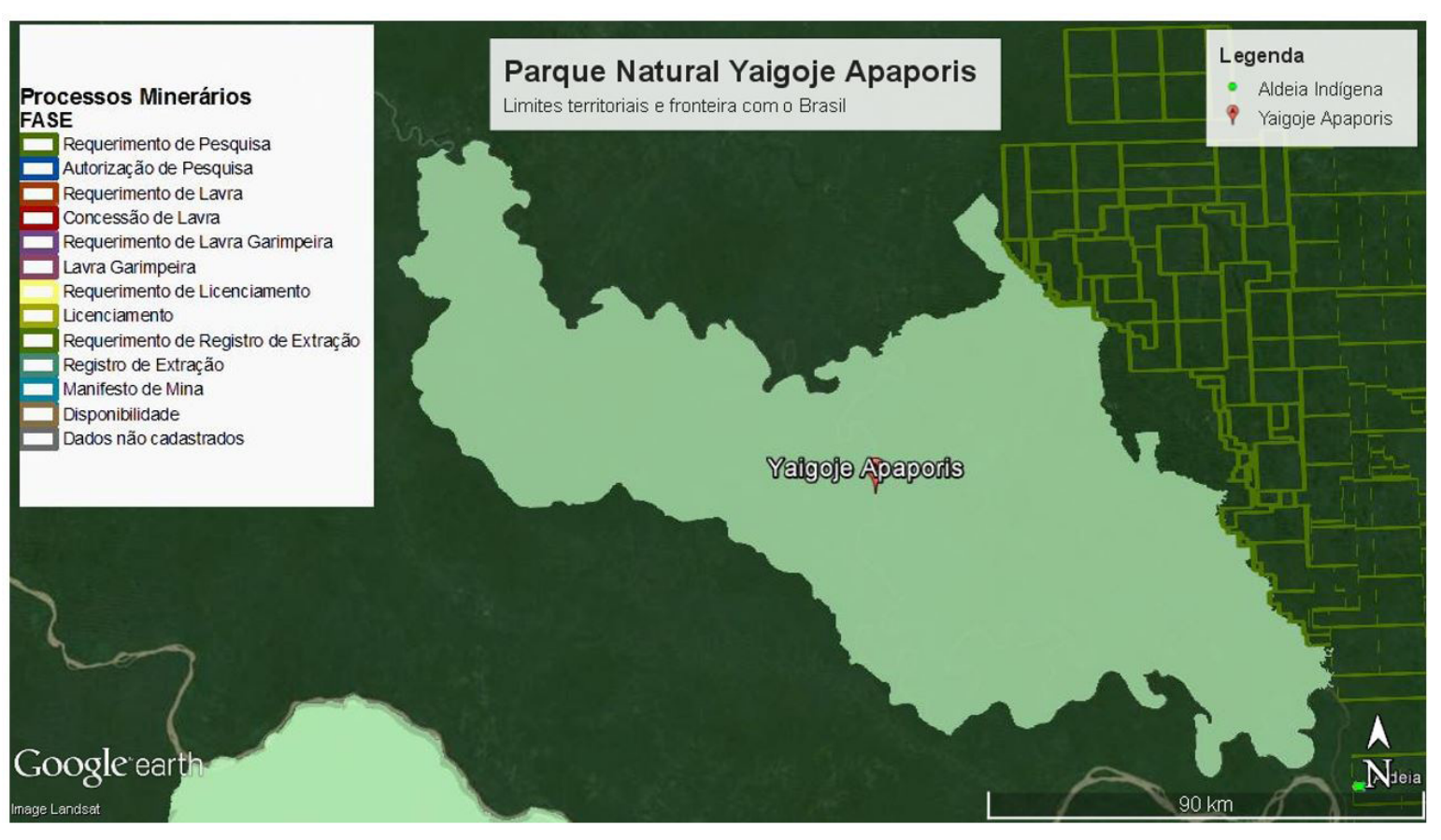

Fonte: DNPM (2015). Imagem de satélite tomada via Google Earth (2014). Consulta em Novembro de 2014. 
T\&P "Paraísos perdidos": investimento estrangeiro direto em mineração e conflitos ecológicos distributivos no Brasil, na Colômbia e no Peru

Em Outubro de 2009 foi criado o Parque Nacional Natural na reserva indígena de Yaigojé Apaporis com o intuito de proteger tanto as comunidades indígenas alocadas no "Complejo Cultural del Vaupés" (Macuna, Tanimuca, Letuama, Cabiyari, Barazano, Yujup Macu e Yauna) quanto fomentar a conexão entre ecossistemas das bacias dos rios Caquetá e Negro, estabelecendo uma política, ao mesmo tempo de conservação ambiental, também de preservação cultural, no qual se retroalimentam, do ponto de vista de suas metas. É importante frisar que, embora apenas uma reserva indígena esteja situada na área do Parque Yaigojé Apaporis, a superposição entre reserva e parque (1.060.602,2 ha) corresponde a 100\% da área total.

O "inusitado" foi que, dois dias depois da criação do Parque Nacional Yaigojé Apaporis, a INGEOMINAS - instituição então responsável pelas licenças e autorizações para exploração mineral - autorizou um título mineiro para a empresa transnacional Cosigo Resources (totalizando 9.973 hectares), produzindo um conflito com artigo 34 da Lei 685 de 2001 que proibia terminantemente a mineração nessas áreas protegidas.

O resultado desde 2009 foi um imbróglio jurídico e político, afetando especialmente as comunidades indígenas, divididas entre aceitar ou não a mineração em suas terras. A situação levou três magistrados da Corte Constitucional colombiana a participar de uma Audiência Pública em pleno Parque para deliberar sobre o status de área protegida ou não do Parque, momento registrado por meio da fotografia, aqui disposta como a Figura 4, em uma das reuniões componentes da Audiência Pública entre indígenas, representantes da Corte Constitucional e a empresa mineradora ${ }^{10}$.

O caso do extrativismo minerário no Parque Nacional Yaigojé Apaporis não é um caso isolado enquanto manifestação da política "locomotora minera" do governo colombiano, cujo objetivo é a atração de mineradoras transnacionais, ainda que o Ministério do Meio Ambiente da Colômbia tenha"congelado"novas titulações minerárias em áreas protegidas por meio da Resolución 1518 de 31 de Agosto de 2012 (ANLA, 2015). É importante frisar que, de acordo com dados do próprio "Catastro Minero" do governo colombiano, a ampliação da mineração de grande escala volta-se para a porção

10 Durante essa Audiência Pública, não se sabe se de forma inocente ou não, Benigno Perilla, líder indígena da Asociación de Capitanes Indígenas de Taraira-Vaupés (Acitava), terminou por admitir publicamente: "[...] que su estrategia legal fue organizada y pagada por la minera de oro canadiense Cosigo Resources, que tiene un título minero dentro de este parque en el Vaupés y que no puede explotarlo mientras el área permanezca protegida." Para maiores informações, veja La Silla Vacia (2014). 
Figura 4. Audiência Pública para debater o status do Parque Nacional Natural Yaigojé Apaporis. Em destaque, três magistrados da Corte Constitucional colombiana Gabriel Mendoza, Nilson Pinilla e Jorge Iván Palacio.

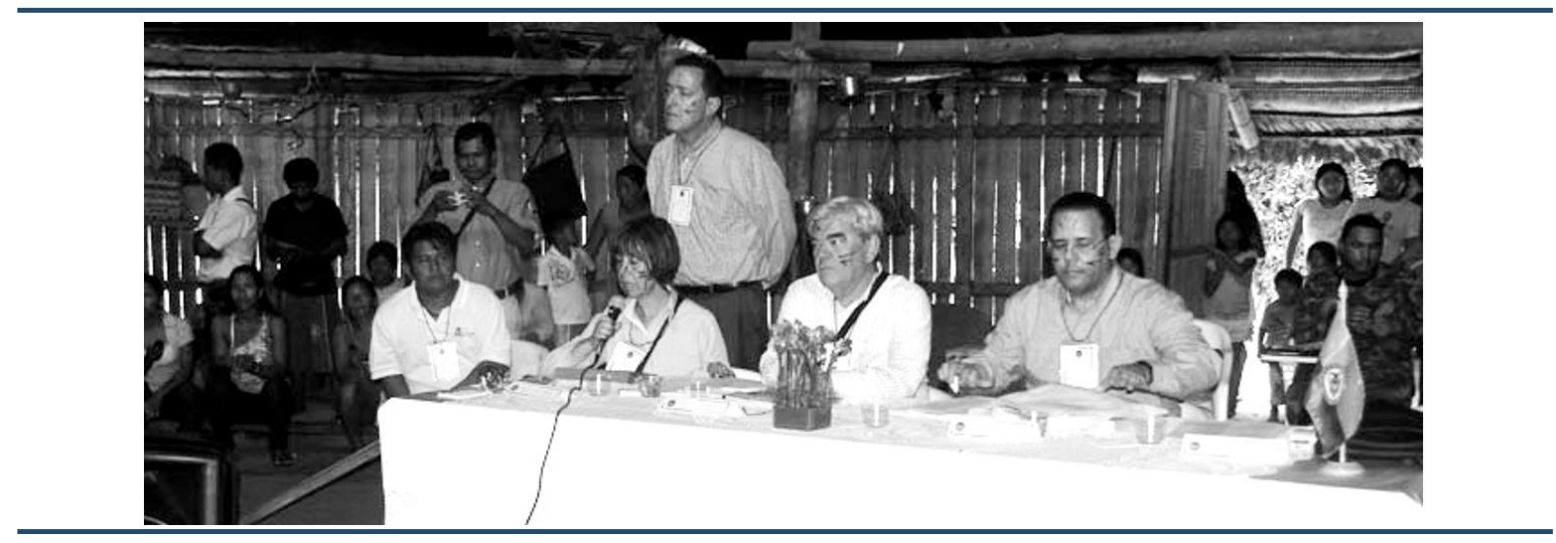

Fonte: Foto disponibilizada por La Silla Vacia (2014).

Figura 5. Potencial de extrativismo minerário na porção amazônica oriental da Colômbia.

ÁREA ESTRATÉGICA MINERA
ZONA ORIENTE

\section{POTENCIAL MINERO}

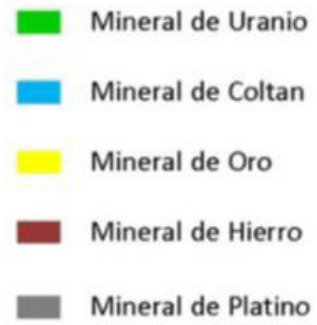

\section{ACTIVIDAD MINERA}

Solicitudes Vigentes: $961 \quad(4,7$ millones de $\mathrm{Ha}$ )

Títulos Mineros: 48 (81 mil $\mathrm{Ha})$

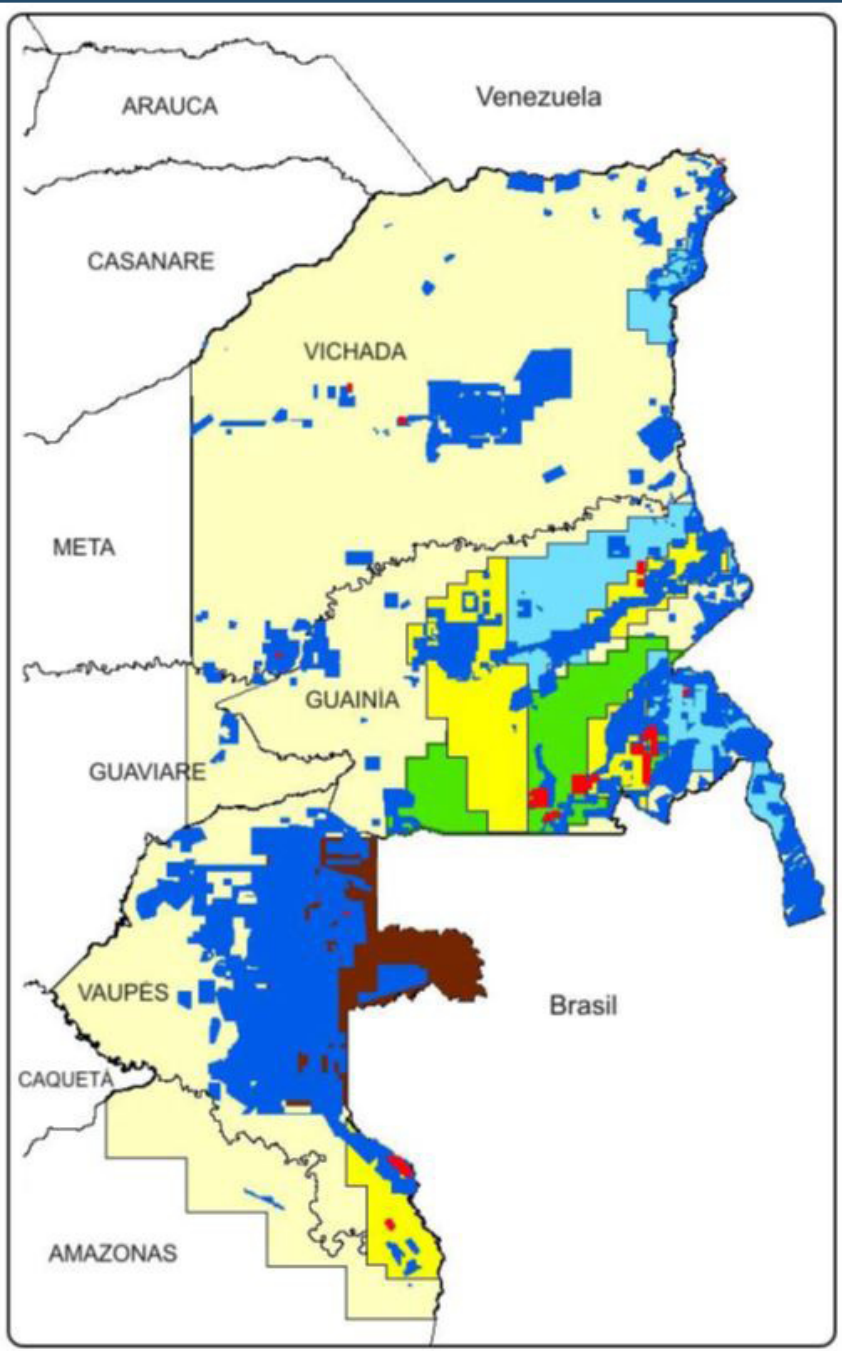


T\&P "Paraísos perdidos": investimento estrangeiro direto em mineração e conflitos ecológicos distributivos no Brasil, na Colômbia e no Peru

amazônica do território colombiano, atingindo diretamente comunidades indígenas e parques naturais, como é possível visualizar na Figura 5.

Alier e Jusmet (2013, p. 363), ao analisarem o perfil de empresas transnacionais envolvidas com passivos ambientais em países latino americanos (especialmente os casos Doe Run na cidade de La Oroya no Peru e Chevron-Texaco na Amazônia equatoriana) observam um padrão dessas empresas e a conjuntura que as mesmas operam: "[...] se trata de una empresa extranjera que produe pasivos ambientales donde la legislación ambiental es menos estricta o el control menos riguroso que en su Estado de origen". Neste caso, como os próprios autores observam, há uma especialização produtiva dos países do Sul, voltados a exploração de commodities, com receitas dessa exploração pelas companhias transnacionais, mas sem incluir na contabilização os passivos ambientais e também sociais gerados pela exploração dessas commodities.

A aposta colombiana (como a brasileira e a peruana, entre outras latino americanas) de "desenvolvimento via extração de recursos naturais" se institucionalizou no Plano "Colombia País Minero 2019": a duplicação da exportação de carvão e a quadruplicação do ouro são dois dos principais objetivos de sua pauta governamental. Esse modelo de "desenvolvimento" não inova, absolutamente. As duas commodities são exportadas sem agregar valor aos produtos (99\% do ouro e entre 92 e 95\% do carvão), resultando na inexistente dinamização da cadeia produtiva local. Outro fator que deve ser levado em consideração é o modelo de extração mineral a céu aberto estimulado pelo governo colombiano, visualizado por meio da imagem de satélite como Figura 6, com suas inúmeras externalidades ambientais.

As externalidades ambientais derivadas da mineração são inúmeras e, mais especificamente, de acordo com Mechi e Sanches (2010, p. 209):

Toda atividade de mineração implica supressão de vegetação ou impedimento de sua regeneração. Em muitas situações, o solo superficial de maior fertilidade é também removido, e os solos remanescentes ficam expostos aos processos erosivos que podem acarretar em assoreamento dos corpos d'água do entorno. A qualidade das águas dos rios e reservatórios da mesma bacia, a jusante do empreendimento, pode ser prejudicada em razão da turbidez provocada pelos sedimentos finos em suspensão, assim como pela poluição causada por substâncias lixiviadas e carreadas ou contidas nos efluentes das áreas de mineração, tais como óleos, graxa, metais pesados. Estes últimos podem também atingir as águas subterrâneas. O regime hidrológico dos cursos d'água e dos aquíferos 
Figura 6. Mineração a Céu Aberto na Colômbia: caso Cerro Matoso S.A.

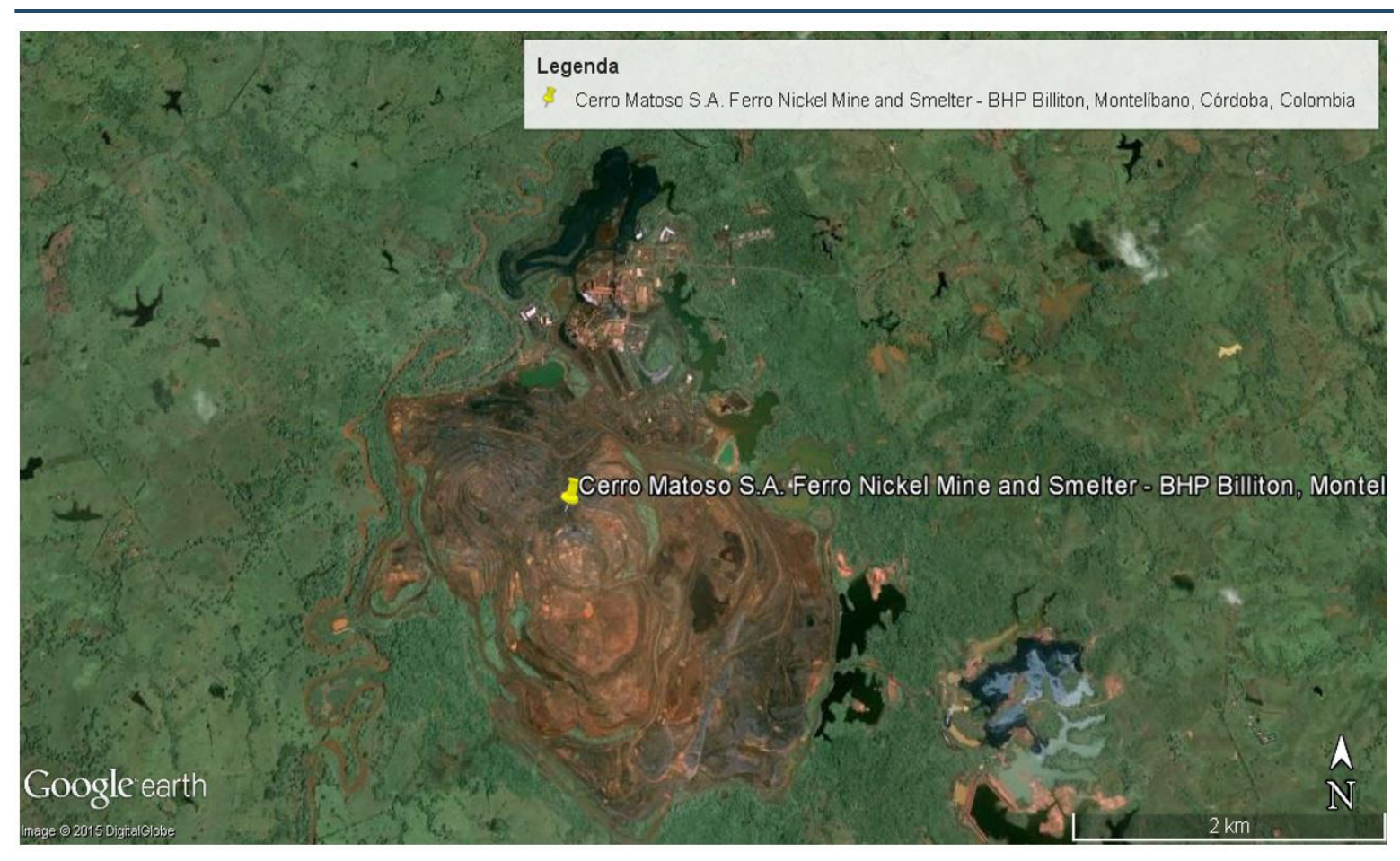

Fonte: Imagem de satélite tomada via Google Earth (2014). Consulta em Novembro de 2014.

pode ser alterado quando se faz uso desses recursos na lavra (desmonte hidráulico) e no beneficiamento, além de causar o rebaixamento do lençol freático.

Ainda que ocorram todas as externalidades ambientais anteriormente citadas, a mineração pesa economicamente no saldo da balança comercial de diversos países, especialmente aqueles com dependência de commodities. E ao ler os planos de desenvolvimento do Brasil, da Colômbia e do Peru há uma clara opção por dar um caráter"sustentável" ao modelo extrativista e, para o caso da mineração, uma "mineração responsável" como algo possível e viável.

O Estado defende o que seria esse modelo de "mineração responsável"e "sustentável", embora mineração e sustentabilidade sejam contradições em termos. As políticas de fomento ao extrativismo minerário nos países pautam-se na premissa de que a mineração sob condução da iniciativa privada é mais capacitada para explorar/explotar bem como para dirimir as externalidades ambientais da mineração. E, diga-se de passagem, em comum aos países o que figura como esse "modelo" é a mega mineração via grandes companhias e não a de pequena escala por meio de pequenos mineradores. 
T\&P "Paraísos perdidos": investimento estrangeiro direto em mineração e conflitos ecológicos distributivos no Brasil, na Colômbia e no Peru

Desta forma, é possível entender a lógica que rege o IED como um ativo político por parte dos governos: a mineração, especificamente, é uma atividade mais eficiente (do ponto de vista econômico) sob exploração privada (especialmente a mineração de grande porte e sob exploração de empresas transnacionais) e, ao mesmo tempo, como atividade econômica promotora do "desenvolvimento" está "despolitizada", o que desqualifica movimentos sociais contrários aos empreendimentos minerários (entre outros) como anti-progresso e potencializa conflitos socioambientais.

No Quadro 4 podemos visualizar o quantitativo desse cenário de conflitos na América Latina.

Na medida que a atração de IED em mineração passa a ser um ativo para políticas de desenvolvimento nos países (e na América Latina como um todo), os conflitos aumentam, especialmente por não haver accountability social nos processos de licenciamento ambiental, exemplificadas pelas Consultas Públicas inexistentes ou, muitas vezes, controladas pelas empresas interessadas na obtenção das licenças ambientais. A busca dos governos brasileiro, peruano e colombiano por maior celeridade no licenciamento ambiental para atrair mais investimento estrangeiro (ou não) privado resulta no enfraquecimento dos mecanismos de regulação e controle, como a consulta

Quadro 4. Conflitos ecológicos distributivos envolvendo mineração na América Latina (2013).

\begin{tabular}{|l|c|}
\hline \multicolumn{1}{|c|}{ País } & Número \\
\hline Argentina & 26 \\
\hline Bolivia & 8 \\
\hline Brasil & 20 \\
\hline Chile & 33 \\
\hline Colombia & 12 \\
\hline Costa Rica & 2 \\
\hline Ecuador & 7 \\
\hline El Salvador & 3 \\
\hline Guatemala & 6 \\
\hline Guiana Francesa & 1 \\
\hline Honduras & 3 \\
\hline México & 26 \\
\hline Nicarágua & 4 \\
\hline Panamá & 6 \\
\hline Paraguai & 1 \\
\hline Perú & 33 \\
\hline Uruguai & 1 \\
\hline
\end{tabular}

Fonte: Elaborado sobre a base de dados do Observatorio de Conflictos Mineros de América Latina (OCMAL, 2015). 
prévia, afetando ainda mais populações campesinas, indígenas e afrodescendentes. De acordo com o Observatório de Conflictos Mineros en el Peru (2014), em torno de 48,6\% das comunidades campesinas no Peru encontram-se sujeitas a concessão de atividades minerárias. Ao observarmos o número de comunidades campesinas sujeitas aos impactos sociais e ambientais da mineração, não é de se espantar em identificar um salto no número de conflitos no país. Hoje, de acordo com a Defensoria del Pueblo do Governo do Peru, existem 152 conflitos ativos e 40 latentes, totalizando ao menos 192 conflitos ecológicos distributivos envolvendo a mineração no Peru.

Por exemplo, em San Juan de Cañaris, localizada na província de Lambayeque no Peru, embora a Resolución Suprema No64 de Janeiro de 1987 emitida pelo Ministerio de Trabajo os reconheça como indígenas e, por isto, todo o procedimento de consulta prévia fosse necessário já que determinado pela Convenção 169 da OIT, a empresa canadense Candente Cooper não realizou a consulta prévia, o que gerou (e ainda gera) inúmeros protestos na região (OBSERVATÓRIO DE CONFLICTOS MINEROS EN EL PERU, 2014). Não é por menos: São três projetos (Cañariaco Norte, Cañariaco Sur y Quebrada Verde) para a exploração de cobre ${ }^{11}$. Perda de qualidade da água, em especial, é a principal externalidade ambiental apontada por campesinos nos projetos envolvendo a mineração de grande escala.

Na Figura 7 destaca-se o caso de Cajamarca, outro Departamento peruano, que tem seu território ocupado em mais de 40\% por concessões mineiras, totalizando 1'331,875.4 hectares. Não é de se estranhar o número de conflitos ecológicos distributivos envolvendo a mineração neste Departamento, além de ter em comum a outros Departamentos peruanos problemas diretos de contaminação de rios e lagos, atingindo diretamente a saúde das populações locais (DAMONTE, 2014).

De acordo com a Defensoria del Pueblo, Cajamarca encontra-se em oitavo lugar na lista de conflitos (com 12 ao total, ativos ou não). Também os casos de Cajamarca não destoam dos restantes da América Latina envolvendo mineração e conflitos ecológicos distributivos. Um em particular chama a atenção, pois envolve uma mineradora transnacional, a Yanacocha composta em seu capital por 51\% (Newmont), Peruvian Buenaventura (44\%) e pelo Banco Mundial (5\%).

11 Para maiores informações, acesse Candente Copper Corp (2015). 
T\&P "Paraísos perdidos": investimento estrangeiro direto em mineração e conflitos ecológicos distributivos no Brasil, na Colômbia e no Peru

Figura 7. Concessões Minerárias no Departamento de Cajamarca no Peru.

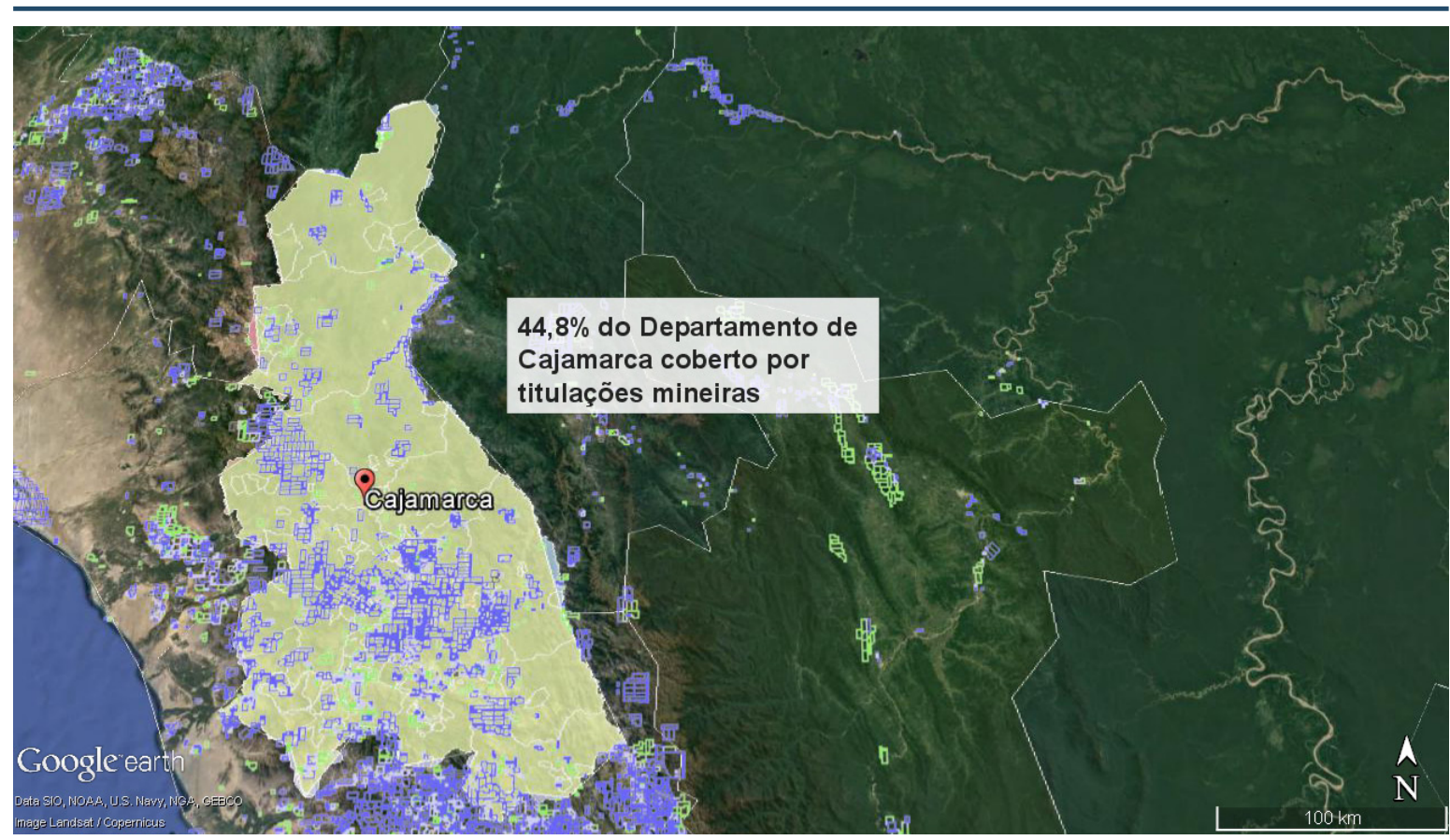

Fonte: INGEMMET (2015).

Figura 8. Mineração de Ouro a Céu Aberto em Cajamarca no Peru pela Mineradora Yanacocha.

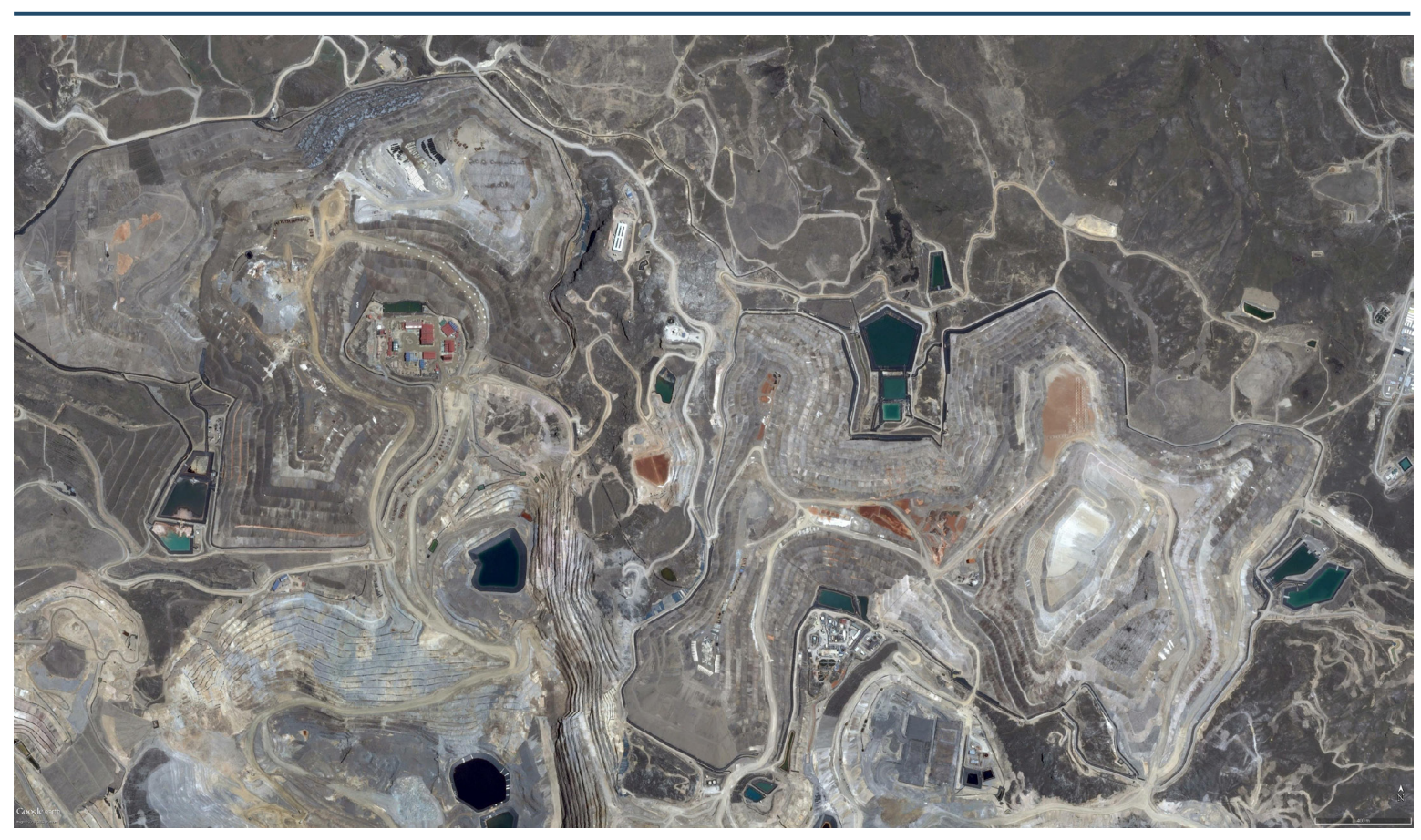

Fonte: Imagem de satélite tomada via Google Earth (2015). Consulta em Julho de 2015. 
Na Figura 8 é possível visualizar o tamanho das áreas diretamente afetadas pelo projeto minerário Yanacocha. Situado entre os distritos de Sorochuco e Huasmí, na província de Celendín e no distrito de La Encañada, na provincia de Cajamarca, o projeto tem por meta a exploração e explotação de jazidas de cobre, ouro e prata e, reforce-se, o território de Cajamarca detém o maior potencial de exploração aurífera da América do Sul. O empreendimento afetará, se completamente consumado, um diverso sistema lagunar andino

E, para "espanto", mesmo diante das bacias hidrográficas serem consideradas pela legislação peruana típicos ecossistemas frágeis, a necessidade de escavar sob "La Laguna El Perol" e remover em torno de 2.000 toneladas de rocha por dia (ao longo de 17 anos), resultará em seca e contaminação por cianureto, águas ácidas entre outros metais pesados, impactando diretamente 5 nascentes de rios, 682 mananciais e 102 poços de água para consumo humano e seis lagos (OBSERVATÓRIO DE CONFLICTOS MINEIROS EN ELPERU, 2014). Na Figura 9 a imagem de satélite registra parte desse intricado e delicado ecossistema lagunar.

Figura 9. "Laguna El Perol” e demais lagos sob alcance dos impactos do projeto "El Conga".

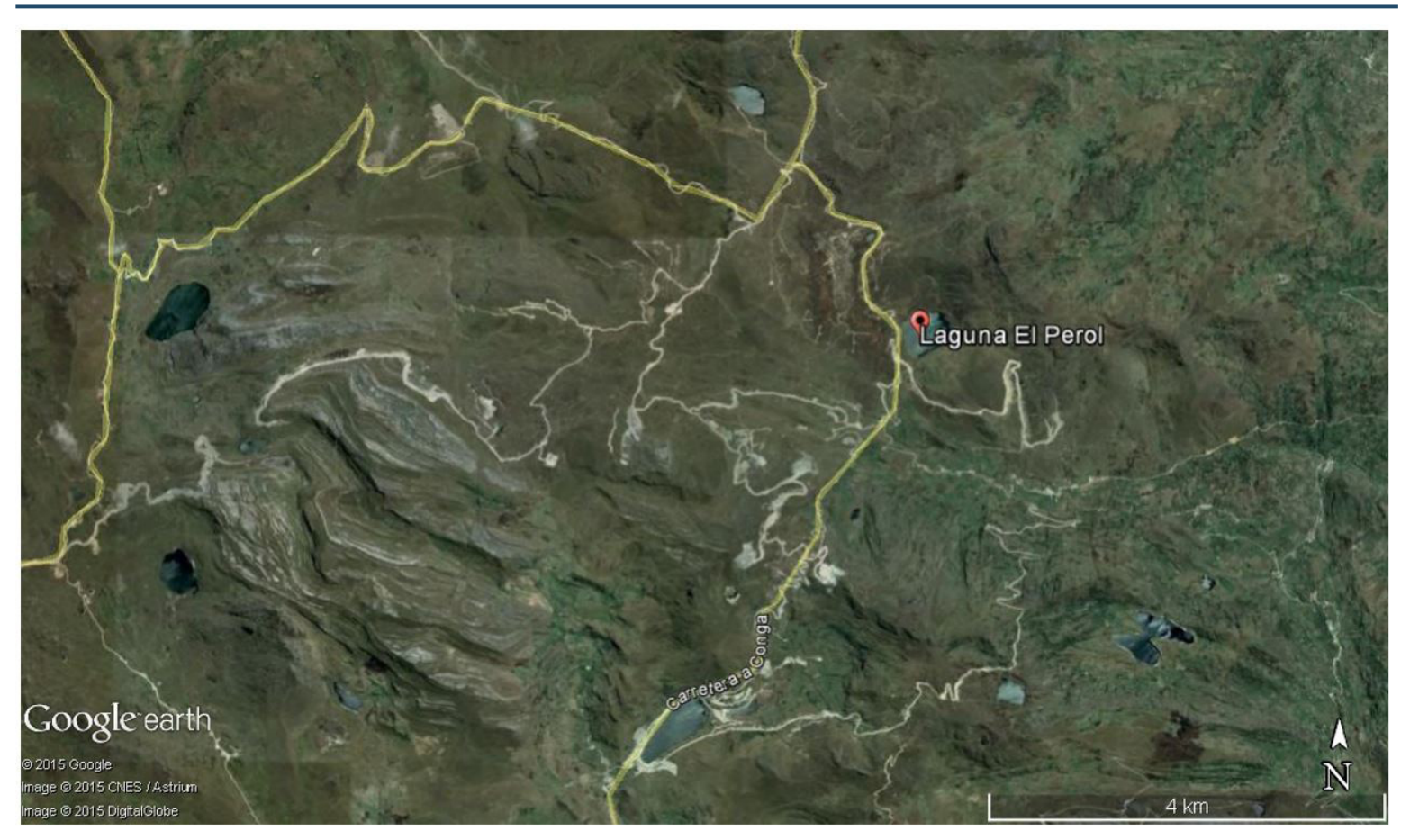

Fonte: Imagem de satélite tomada via Google Earth (2015). Consulta em Setembro de 2015. 
T\&P "Paraísos perdidos": investimento estrangeiro direto em mineração e conflitos ecológicos distributivos no Brasil, na Colômbia e no Peru

Embora com legislação específica de direito à consulta prévia aos povos indígenas e originários, há neste cenário de conflitos ecológicos distributivos a fragilidade de mecanismos político-institucionais de accountability social que permitam um processo consultivo e deliberativo livre sobre os impactos dos empreendimentos minerários no Peru. A ausência ou ineficiência dos mecanismos institucionais de representatividade e deliberação diante de grandes empreendimentos extrativistas terminam estimular a eclosão (ou reforço social) de movimentos de resistência. Na Figura 10 é possível visualizar a dimensão de um dos inúmeros protestos contra a mega mineração no Peru.

E ao percebermos o conjunto de conflitos ecológicos distributivos em Cajamarca, no Peru (e bem poderiam ser em Juruti Velho no Pará, Brasil, ou em Putumayo ou Vaupés, na Colômbia), podemos identificar uma mudança no padrão de reações sociais ao modelo extrativista, anteriormente mais conjunturais e agora mais estruturais. Ainda que as demandas sejam fraccionadas e, consequentemente, as negociações envolvendo os atores sociais e os agentes econômicos empreendedores, mediadas por um Estado

Figura 10. Protesto de Campesinos em Cajamarca contra a mineração de ouro a céu aberto promovida pela Companhia Mineira Yanacocha.

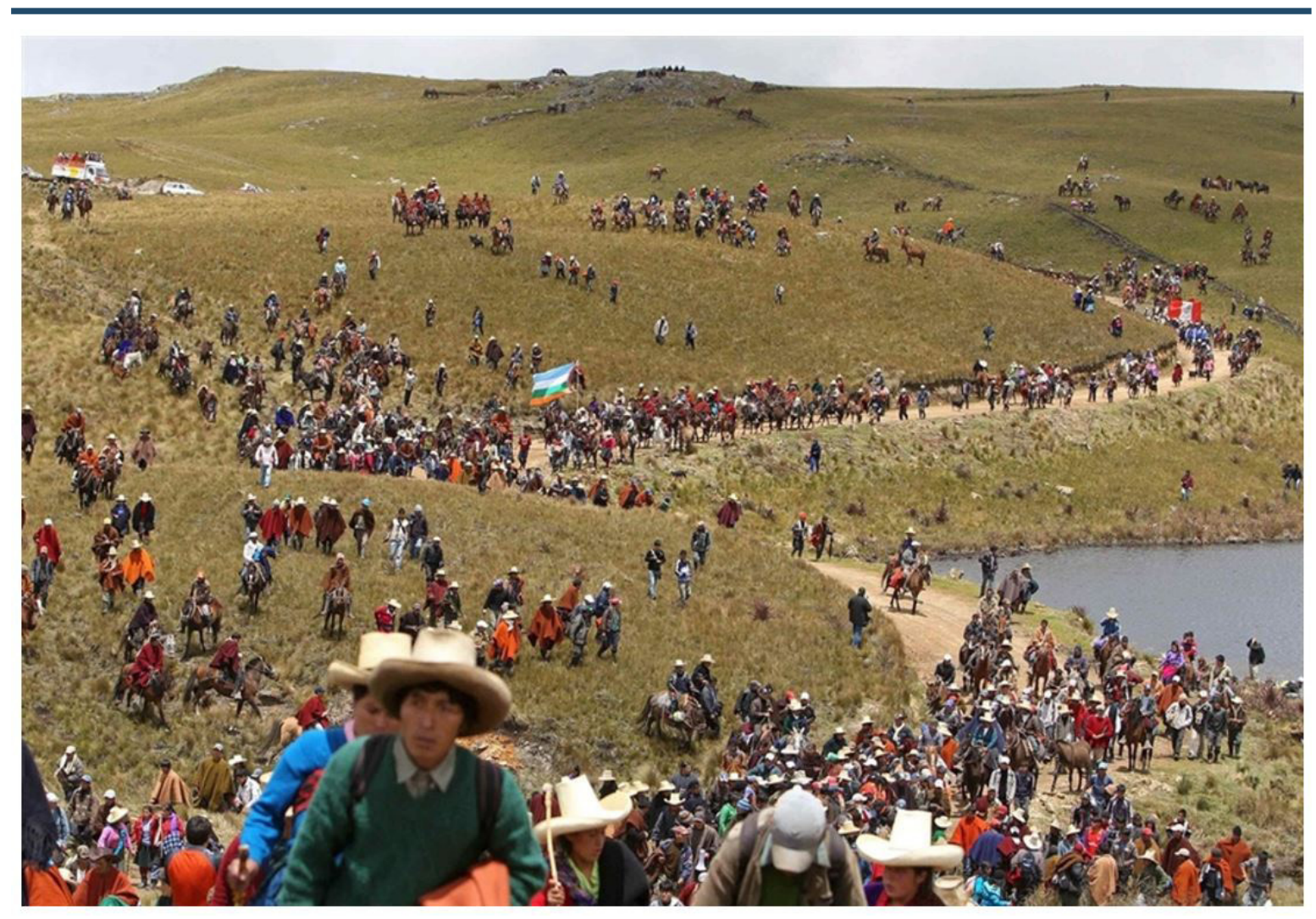

Fonte: Foto de Luisa Trujillo. 
indutor do extrativismo como "motor do desenvolvimento" se tornem mais ainda mais frágeis.

Embora tomemos que a democracia é a institucionalidade política necessária para melhor gestão dos bens e serviços ambientais e ecossistêmicos (RODRIGUES et al., 2015), Collier e Hoeffler (2004) apontam que ela pode ser insuficiente lato sensu e até mesmo contraproducente se os arranjos eleitorais não consideram um sistema de pesos e contrapesos que controlem o acesso e uso do poder político. O mecanismo da Consulta Prévia é insuficiente para uma adequada accountability social e, mesmo assim, ainda sofre inúmeras fragilidades nos três países. Portanto, além de se perder ambiental e economicamente oportunidades de ampliação e redistribuição de riqueza oriunda da mineração, os indicadores sociais não avançam, como atestam os dados dos departamentos colombianos e peruanos, por exemplo e nem a qualidade democrática avaliada pela efetivação da Consulta Prévia às populações atingidas por empreendimentos minerários é alcançada.

\section{Considerações finais}

O aumento de IED, como já observado, fortemente concentrado em produtos intensivos de recursos naturais (agroindústria, processamento de recursos minerais e energéticos), fomentou na América Latina uma pauta exportadora acentuadamente dependente de produtos primários e intensivos em recursos naturais, em atividades econômicas acentuadamente degradadoras do meio ambiente e com instituições e mecanismos político-institucionais pouco accountables que permitissem aos atingidos e atingidas pelos empreendimentos pudessem deliberar (e não apenas ser consultados, quando o eram) sobre os impactos socioambientais que suas comunidades e ecossistemas sofreriam com a mineração de grande ou mesmo pequeno porte, por exemplo.

O uso do IED como um ativo político de desenvolvimento pode ser entendido como um moderno "canto da sereia". O IED por si só não estimula o crescimento geral da economia ou favorece níveis mais elevados de proteção ambiental de um determinado país, pois são necessárias políticas nacionais que em conjunto auxiliem no desenvolvimento da região, o que não ocorre, grosso modo, nas regiões diretamente afetadas pela "megamineração". 
T\&P "Paraísos perdidos": investimento estrangeiro direto em mineração e conflitos ecológicos distributivos no Brasil, na Colômbia e no Peru

A mineração, neste sentido, incide de maneira definitiva em pautas como o uso e distribuição tradicional das comunidades sobre o território em todas as suas implicações possíveis: a saúde das populações atingidas, a perda de qualidade ambiental e vitalidade dos ecossistemas, a competição no uso de outros recursos naturais como a pesca, agricultura e turismo, a organização social e política das comunidades atingidas direta ou mesmo indiretamente pela mineração, potencializando não o desenvolvimento local, mas a perda de oportunidade para o mesmo, haja vista a distância existente entre quem licencia os empreendimentos minerários, as empresas mineradoras e as populações atingidas.

No entanto, como já observado, tal liberalização econômica tem despertado preocupações e protestos disseminados pelos países que recebem essas mineradoras, pois os resultados que podem ser diagnosticados nos países que mais flexibilizaram suas legislações e mecanismos institucionais de controle não correspondem às expectativas de associação entre o crescimento econômico e o desenvolvimento social.

Um dos efeitos de políticas de desenvolvimento baseadas em extração de recursos naturais tanto no Brasil quanto na Colômbia e no Peru é a baixa responsividade ambiental no controle e regulação da atividade minerária, o que potencializa os conflitos envolvendo a mineração, como já foi observado. Para identificar essa baixa responsividade os procedimentos de licenciamento ambiental são uma peça fundamental, especialmente porque são eles, como instrumentos de política ambiental, que determinam a operação ou não de alguma atividade minerária, o que resulta - quando na negativa da licença ambiental - na queixa das empresas mineradoras (ou mesmo de pessoas físicas) para "maior flexibilidade e celeridade" no licenciamento ambiental, cenário este que, se consolidado, trará ainda mais conflitos às regiões afetadas pelo extrativismo minerário.

Tanto a Amazônia quanto os Andes são visualizados pelas políticas governamentais de Brasil, Colômbia e Peru como espaços vazios de desenvolvimento, aptos a serem capturados por políticas desenvolvimentistas pautadas num "extrativismo redentor" que, tal qual uma oportunidade "de ouro", se faz presente para alavancar tanto o desenvolvimento local quanto o crescimento econômico de seus países. Entretanto, como foi indicado neste trabalho, o preço a se pagar é alto nas comunidades que suportam esses empreendimentos minerários, seja do ponto de vista ambiental ou social. Os recursos naturais, para as comunidades locais, permanecem uma maldição. 


\section{Referências}

ADES, A.; DI TELLA, R. Rents, competition and corruption. The American Economic Review, v. 89, n. 4, p. 982-993, 1999. http://dx.doi.org/10.1257/aer.89.4.982.

ALCOA. Projeto Juriti. São Paulo, 2004. Disponível em: <http://www.alcoa.com/brazil/pt/ environment/pdfs/folder.pdf>. Acesso em: 22 de set. 2015.

ALIER, J. M.; JUSMET, J. R. Economia ecológica y política ambiental. México: FCE, 2013.

ARELLANOS, J. A thoroughly modern resource curse? The new natural resource policy agenda and the mining revival in Peru. Brighton: Institute of Development Studies, 2008. Working Paper, 300.

ATLAS DO DESENVOLVIMENTO HUMANO NO BRASIL. 2014. Disponível em: <http://www. atlasbrasil.org.br/2013/>. Acesso em: 21 dez. 2014

AUTORIDAD NACIONAL DE LICENCIAS AMBIENTALES - ANLA. Bogotá, 2015. Disponível em: $<$ http://www.anla.gov.co/contenido/contenido.aspx?catID=1373\&conID=8044>. Acesso em: 22 de set. 2015.

AUTY, R. M.; WARHURST, A. Sustainable development in mineral exporting economies. Resources Policy, v. 19, p. 14-29, 1993.

BANCO NACIONAL DE DESENVOLVIMENTO ECONÔMICO E SOCIAL - BNDES. Financiamento para ALCOA. Brasília, 2015. Disponível em: <http://www.bndes.gov.br/SiteBNDES/bndes/system/ modules/br.gov.bndes.prototipo/templates/tmp_resultado_busca.jsp?index=BNDES\&query_ bndes=alcoa\&query=alcoa $>$. Acesso em: 22 de set. 2015.

BARROS, C. J. Juruti: um pacto possível? São Paulo: Agência de Reportagem e Jornalismo Investigativo, 2012. Disponível em: <http://www.apublica.org/amazoniapublica/tapajos/ juruti-um-pacto-possivel/>. Acesso em: 14 jul. 2015

BENAVIDES, J. et al. Impacto de las regalias en la inversión de las entidades territoriales. Bogotá: Fedesarrollo, 2000.

BRASIL. Presidência da República. Lei no 7.990, de 28 de dezembro de 1989. Institui, para os Estados, Distrito Federal e Municípios, compensação financeira pelo resultado da exploração de petróleo ou gás natural, de recursos hídricos para fins de geração de energia elétrica, de recursos minerais em seus respectivos territórios, plataformas continental, mar territorial ou zona econômica exclusiva, e dá outras providências. Diário Oficial [da] República Federativa do Brasil, Brasília, DF, 28 dez. 1989. Disponível em: <http://www.planalto.gov.br/ccivil_03/ leis/L7990.htm>. Acesso em: 10 jun. 2015.

BRASIL. Ministério Público Federal. Brasília, D.F., 2015. Disponível em: <http://noticias.pgr.mpf. mp.br/noticias/noticias-do-site/copy_of_meio-ambiente-e-patrimonio-cultural/consultoriavai-avaliar-quanto-alcoa-deve-a-ribeirinhos-de-juruti>. Acesso em: 14 jul. 2015.

CANDENTE COPPER CORP. Cañariaco Norte Copper Project. Vancouver, 2015. Disponível em: <http://www.candentecopper.com/s/PeruProjects_Canariaco.asp>. Acesso em: 13 jul. 2015. 
T\&P "Paraísos perdidos": investimento estrangeiro direto em mineração e conflitos ecológicos distributivos no Brasil, na Colômbia e no Peru

COMISIÓN ECONÓMICA PARA AMÉRICA LATINA - CEPAL. Estudio económico de América Latinay el Caribe. Santiago, 2012. Disponível em: <http://www.cepal.org/cgibin/getProd.asp?xml=/ de/agrupadores_xml/aes252.xml\&xsl=/agrupadores_xml/agrupa_listado.xsl>. Acesso em: 14 jun. 2014.

COMISIÓN ECONÓMICA PARA AMÉRICA LATINA - CEPAL. Inversión extranjera directa. Santiago, 2015. Disponível em: <http://www.cepal.org/es/temas/inversion-extranjera-directa>. Acesso em: 22 set. 2015.

COLLIER, P.; HOEFFLER, A. Greed and grievance in civil wars. Oxford Economic Papers, v. 56, n. 4, p. 663-695, 2004. http://dx.doi.org/10.1093/oep/gpf064.

COLOMBIA. Decreto no 1728 de 06 de agosto de 2002, derogado por el art. 29, decreto Nacional 1180 de 2003. Por el cual se reglamenta el Título VIII de la Ley 99 de 1993 sobre la Licencia Ambiental. Diario Oficial, Bogotá, no 44893, 07 ago. 2002. Disponível em: <http://www. alcaldiabogota.gov.co/sisjur/normas/Norma1.jsp?i=5548>. Acesso em: 20 ago. 2014

COLOMBIA. Ley no 963 de 2005. Por la cual se instaura una ley de estabilidad jurídica para los inversionistas en Colombia. República de Colombia - Gobierno Nacional, Bogotá, 8 jul. 2005a. Disponível em: <http://www.mincit.gov.co/loader.php?IServicio=Documentos\&lFuncion =verPdf\&id=60872\&name=Ley_963_08_07_05.pdf\&prefijo=file>. Acesso em: 22 jul. 2014

COLOMBIA. Ministerio de Ambiente, Vivienda y Desarrollo Territorial. Decreto no 1220, de 21 abril de 2005. Por el cual se reglamenta el Título VIII de la Ley 99 de 1993 sobre licencias ambientales. Diario Oficial, Bogotá, no 45890, 25 abr. 2005b. Disponível em: <http://www. ideam.gov.co/documents/24024/36843/Decreto_1220+de+2005.pdf/9127b232-821546aa-8793-c0d3ec21b076>. Acesso em: 12 ago. 2014

COLOMBIA. Análisis PND 2010-2014. Bogotá: Sector Minero Energético, 2011 a. Disponível em: <http://www.contraloriagen.gov.co/web/guest/minas-y-energia/-/asset_publisher/wQ00/ content/analisis-pnd-2010-2014-sector-minero-energetico;jsessionid=c49d035748aa9f0e3 a0ad0876aad?redirect=\%2Fweb\%2Fguest\%2F minas-y-energia>. Acesso em: 22 set. 2015.

COLOMBIA. Sistema General de Regalias. Acto legislativo no 05 de 18 de julho de 2011. Por el cual se constituye el sistema general de regalías, se modifican los artículos 360 y 361 de la constitución política y se dictan otras disposiciones sobre el régimen de regalías y compensaciones. República de Colombia - Gobierno Nacional, Bogotá, 18 jul. 2011 b. Disponível em: <https://www.sgr.gov.co/LinkClick.aspx?fileticket=E9g2P8ImArE\%3d\&tabid=95\&m $\mathrm{id}=517>$. Acesso em: 09 ago. 2015

COLOMBIA. Catastro Minero Nacional y Registro Minero Nacional. Bogota: Sistema de Información Minero Colombiano, 2014. Disponível em: <http://www.simco.gov.co/Inicio/ CatastroMineroColombiano/tabid/107/Default.aspx>. Acesso em: 02 abr. 2015

DAMONTE, G. El modelo extractivo peruano: discursos, políticas y la reproduccion de desigualdades sociales. In: GOBEL, B.; ULLOA, A. (Orgs.). Extractivismo minero em Colombia y América Latina. Bogotá: Universidad Nacional de Colombia. Berlin: Ibero-Amerikanisches Institut, 2014. 
DAVIS, G. A. The mineral sector, sectoral analysis, and economic development. Resources Policy, v. 24, n. 4, p. 217-228, 1998. http://dx.doi.org/10.1016/S0301-4207(98)00034-8.

DEFENSORIA DEL PUEBLO COLOMBIA. 2015. Disponível em: <http://www.defensoria.gov.co/. > . Acesso em: 14 jun 2015.

DEPARTAMENTO NACIONAL DE PLANEACIÓN - DNP. Boletín Regalías al día. Bogotá, 2009. Disponível em: <https://www.sgr.gov.co/LinkClick.aspx?fileticket=KHqouj9NhRs\%3D\&ta bid=109>. Acesso em: 14 jun. 2015.

DEPARTAMENTO NACIONAL DE PLANEACIÓN - DNP. Mapa das regalías em Colombia. Bogotá, 2015. Disponível em: <http://maparegalias.sgr.gov.co/\#/>. Acesso em: 08 jul. 2015.

DEPARTAMENTO NACIONAL DE PRODUÇÃO MINERAL - DNPM. Cadastro Mineiro. Brasília, D.F., 2015. Disponível em:<http://www.dnpm.gov.br/assuntos/ao-minerador/cadastro-mineiro>. Acesso em: 22 de set. 2015.

ESPINOSA, A. C. G. La sociedade civil como "conjuro" a la maldición de los recursos naturales?: vigilância ciudadana a la renta extractiva em Colombia y Peru. In: ESPINOSA, A. C. G. (Org.). Los retos de la gobernanza minero-energética. Bogotá: Universidad Externado de Colombia, 2013.

FUNDAÇÃO OSWALDO CRUZ - FIOCRUZ. Mapa da injustiça ambiental e saúde no Brasil. Conflitos entre a atividade mineradora e comunidades tradicionais extrativistas no extremo oeste do Pará: deterioração de igarapés, lagos e corte de matas e castanheiras. Rio de Janeiro, 2009. Disponível em: <http://www.conflitoambiental.icict.fiocruz.br/index.php?.pag=ficha\&cod=76>. Acesso em: 22 set. 2015.

GOOGLE EARTH. Seleção de imagens de satélite entre os anos de 2000-2015. 2014. (Software livre). GOOGLE EARTH. Seleção de imagens de satélite entre os anos de 2000-2015. 2015. (Software livre). INSTITUTO CHICO MENDES DE BIODIVERSIDADE - ICMBIO. Plano de manejo da Floresta Nacional de Saracá-Taquera, Estado do Pará - Brasil. Brasília, D.F., 2001. Disponível em: <http://www. icmbio.gov.br/portal/images/stories/docs-planos-de-manejo/pm_flona_saraca_taquera. pdf>. Acesso em: 21 set. 2015.

INSTITUTO GEOLOGICO MINERO Y METALÚRGICO - INGEMMET. Ministerio de Energía y Minas del Gobierno de Peru. Lima, 2015. Disponível em: http://www.ingemmet.gob.pe/form/Inicio. aspx>. Acesso em: 22 jul. 2015.

INSTITUTO NACIONAL DE ESTADÍSTICA E INFORMÁTICA DO PERU - INEI. Minería (2007-2010). Lima, 2007. Disponível em: <http://www.inei.gob.pe/estadisticas/indice-tematico/mining1/>. Acesso em: 10 maio 2015.

INSTITUTO DO PATRIMONIO HISTÓRICO E ARTÍSTICO NACIONAL - IPHAN. Convenção no 169 sobre povos indígenas e tribais e resolução referente à ação da OIT. Brasilia: OIT, 2011. Disponível em: <http://portal.iphan.gov.br/uploads/ckfinder/arquivos/Convencao_169_OlT.pdf>. Acesso em: 06 jun. 2014. 
T\&P "Paraísos perdidos": investimento estrangeiro direto em mineração e conflitos ecológicos distributivos no Brasil, na Colômbia e no Peru

INSTITUTO PERUANO DE ECONOMIA - IPE. San Isidro, 2012. Disponível em: <www.ipe.org.pe>. Acesso em: 22 jul. 2015.

LA SILLA VACIA. La minera que quería tumbar el parque amazónico. 2014. Disponível em: $<$ http://lasillavacia.com/historia/la-minera-que-estaba-detras-de-la-tutela-al-parqueamazonico-46563>. Acesso em: 05 jul. 2015.

LIMA, D. R.; MOTA, J. A. A produção do alumínio primário na Amazônia e os desafios da sustentabilidade. Boletim Regional, Urbano e Ambiental, IPEA, jul. 2009. Disponível em: <http://www.ipea.gov.br/portal/index.php?option=com_content\&view=article\&id=1 573\&ltemid=7>. Acesso em: 21 set. 2015.

MECHI, A.; SANCHES, D. L. Impactos ambientais da mineração no Estado de São Paulo. Estudos Avançados, v. 24, n. 68, p. 209-220, 2010. http://dx.doi.org/10.1590/S0103-40142010000100016.

MORALES, J. F. Políticas mineras en Colombia. Bogotá: Instituto Latino Americano para uma Sociedad y un Derecho Alternativos, 2012.

O'FAIRCHEALLAIGH, C; GIBSON, G. Economic risk and mineral taxition on Indigenous lands. Resources Policy, v. 37, p. 10-18, 2012.

OBSERVATORIO DE CONFLICTOS MINEROS DE AMÉRICA LATINA - OCMAL. 2015. Disponível em: <http://www.conflictosmineros.net/>. Acesso em: 25 mar. 2015.

OBSERVATÓRIO DE CONFLICTOS MINEROS EN EL PERU. Informes semestrales. 2014. Disponível em: <http://www.conflictosmineros.org.pe/reportes>. Acesso em: 05 jul 2015.

PERU. Decreto supremo n. 060-2013-PCM. Aprueban disposiciones especiales para la ejecución de procedimientos administrativos y otras medidas para impulsar proyectos de inversión pública y privada. Lima, 2013. Disponível em: <http://www.minem.gob.pe/minem/archivos/ DS\%20060-2013-PCM-Tiempos\%20de\%20evaluacion\%20de\%20los\%20ElA.pdf>. Acesso em: 14 jul. 2015

RADETZKI, M. Regional development benefits of mineral projects. Resources Policy, v. 8, n. 3, p. 193-200, 1982. http://dx.doi.org/10.1016/0301-4207(92)90036-9.

RETTBERG, A.; ORTIZ-RIOMALO, J. F.; YAÑEZ-QUINTERO, S. Legislando minas: breve recuento de la legislación minera en Colombia (1829-2001). Bogotá: Universidad de los Andes, 2014. Serie Documentos Cede. Disponível em: <http://www.colombiapuntomedio.com/Portals/0/ Archivos2014/MineriaNal2014/Legislaci\%C3\%B3n\%20Minera\%20U\%20de\%20los\%20 Andes.pdf>. Acesso em: 24 out. 2014.

RODRIGUES, D. F. et al. A sustentável leveza da democracia? Os efeitos da qualidade democrática sobre o desempenho ambiental. Desenvolvimento e Meio Ambiente, v. 33, p. 81-99, 2015. http://dx.doi.org/10.5380/dma.v33i0.36875.

ROSS, M. Extractive sectors and the poor. Washington, DC: Oxfam America, 2001. 
SISTEMA DE INFORMACIÓN MINERO COLOMBIANA - SIMCO. Bogota, 2014. Disponível em: <http:// www.simco.gov.co/simco/Informaci\%C3\%B3nparalnversionistas/Informaci\%C3\%B3nGeneral/ tabid/57/Default.aspx>. Acesso em: 22 jul. 2015.

WANDERLEY, L. J. M. Deslocamento compulsório e estratégias empresariais em áreas de mineração: um olhar sobre a exploração de bauxita na Amazônia. Revista IDeAS - Interfaces em Desenvolvimento, Agricultura e Sociedade, v. 3, n. especial, p. 475-509, 2009.

WRIGHT, G. Resource-based growth then and now. 2001. Working Paper. Disponível em: <citeseerx. ist.psu.edu/viewdoc/download?doi=10.1.1.491.5679\&rep=rep1\&type=pdf>. Acesso em: 22 jul. 2015.

Recebido: 22 jul., 2015

Aceito: 10 out., 2016 